\title{
A Multihazard Assessment of Age-Related Weather Vulnerabilities
}

\author{
Jonathan M. Garner, William C. Iwasko, ${ }^{\text {a }}$ Tyler D. Jewel, Brad R. Charboneau, \\ Alex A. DodD, AND KATHLEEN M. ZonTOS \\ NOAA/National Weather Service, Eureka, California
}

(Manuscript received 25 September 2019, in final form 14 March 2020)

\begin{abstract}
Weather fatalities for all age groups were examined for the period 1996-2018 using NOAA Storm Data. Vulnerabilities due to limited mobility that inhibited evacuation from a hazardous environment were observed for the very young and the very old. Those situations included heat- and cold-related hazards, tropical cyclones, and wildfires. Vulnerabilities associated with unrestricted mobility occurred in teenage through middle-aged groups, who were more exposed to fatal outcomes in the surfzone, mountain, winter-driving, and lightning environments. There is evidence that vulnerable members of society who received help from family, neighbors, and their community were more likely to avoid potentially fatal weather events, whereas those who were socially isolated were more likely to succumb. National Weather Service programs, such as WeatherReady Nation, and other initiatives like the Community Emergency Response Team could potentially aid in reducing weather fatalities by encouraging communities to take a more proactive approach in ensuring physically vulnerable populations like the elderly receive assistance during hazardous weather events. Furthermore, weather-messaging strategies should be flexible enough to target populations who are vulnerable to specific hazards.
\end{abstract}

\section{Introduction}

The National Oceanic and Atmospheric Administration's (NOAA) National Weather Service (NWS) 2019-22 Strategic Plan (NWS 2019a) tasks the NWS with preparing the United States for the impacts associated with weather, water, and climate. The NWS uses a "whole community" approach to achieve a weather-ready nation that spans all levels of government, the weather and climate industry, communities, and household members. Furthermore, the NWS promotes weather readiness and preparedness through impact-based decision support services (IDSS) that are composed of forecast advice and interpretative services provided to core government partners who make weather-related decisions when lives and property are at stake (NWS 2018).

One element of IDSS is a focus on the safety of vulnerable populations-a topic that is explored in depth in this paper (see Table 1 for a list of key term definitions).

\footnotetext{
${ }^{a}$ Current affiliation: NOAA/National Weather Service, Lubbock, Texas.
}

Corresponding author: Jonathan M. Garner, jonathan.garner@ noaa.gov
In particular, emphasis is given to how limitations on mobility and perception may have enhanced the potential for fatal outcomes. Rosso et al. (2013) defines mobility as the ability of an individual to purposively move about their environment. If that definition is applied to the context of a hazardous weather scenario, mobility determines whether a person is physically capable or incapable of removing themselves from the hazardous environment. Those incapable of avoiding a hazard cannot move at all or cannot move in a sufficient amount of time to avoid a deadly outcome. In addition, mental and economic factors can inhibit individuals from avoiding hazardous situations.

Poor physical mobility can raise the potential for fatalities during certain meteorological settings. For example, Root (1937) documented elderly retired "shut-ins" as being susceptible to urban heat waves as early as the 1930s, and that topic was examined in even greater detail by Changnon et al. (1996), among others. The exposure to weather-related health threats by such vulnerable groups as the elderly is influenced by their ability or choice to evacuate or shelter in place (Gamble et al. 2016). More generally, Clarke et al. (2015) note that mobility is important for independence and quality of life, and their research showed that persons with 
TABLE 1. List of key terms defined by the Intergovernmental Panel on Climate Change related to human vulnerability to hazardous weather (Lavell et al. 2012).

\begin{tabular}{|c|c|}
\hline Term & Definition \\
\hline Hazard & $\begin{array}{l}\text { The potential occurrence of a natural or human-induced physical event that may cause loss of life, injury, or other health } \\
\text { impacts, as well as damage and loss to property, infrastructure, livelihoods, service provision, and environmental } \\
\text { resources }\end{array}$ \\
\hline Disaster risk & $\begin{array}{l}\text { The likelihood over a specified time period of severe alterations in the normal functioning of a community or a society } \\
\text { due to hazardous physical events interacting with vulnerable social conditions, leading to widespread adverse human, } \\
\text { material, economic, or environmental effects that require immediate emergency response to satisfy critical human } \\
\text { needs and that may require external support for recovery }\end{array}$ \\
\hline Exposure & $\begin{array}{l}\text { The presence of people, livelihoods, environmental service and resources, infrastructure, or economic, social, or cultural } \\
\text { assets in places that could be adversely affected by physical events and that, thereby, are subject to potential future } \\
\text { harm, loss, or damage }\end{array}$ \\
\hline Vulnerability & $\begin{array}{l}\text { The propensity or predisposition to be adversely affected by a weather event due to a person or group's situation that } \\
\text { influences their capacity to anticipate, cope with, resist, and recover from the adverse effects of physical events }\end{array}$ \\
\hline Resilience & $\begin{array}{l}\text { The ability of a system and its component parts to anticipate, absorb, accommodate, or recover from the effects of a } \\
\text { potentially hazardous event in a timely and efficient manner, including through ensuring the preservation, restoration, } \\
\text { or improvement of its essential basic structures and functions }\end{array}$ \\
\hline
\end{tabular}

limited mobility suffered more severe impacts during times of hazardous weather. The basic function of moving from one place to another is essential in performing minimal tasks necessary to survive a weather hazard. This is true for short-term threats such as tornadoes as well as longer-term threats associated with climate change (Tacoli 2009).

However, for a person to avoid a hazard by capitalizing on their mobility, they must first perceive the threat. Carbon (2014) states that the main task of human perception is to amplify and strengthen sensory inputs to be able to perceive, orient, and act very quickly, specifically, and efficiently - thus perception influences mobility. Perception may be limited by diminished cognitive abilities related to such factors as dementia or apathy; however, perception could also be limited by a lack of environmental clues such that a physically and mentally fit person puts or finds themselves in a threat zone unknowingly. A lack of threat perception can contribute to fatal events, such as those associated with lightning (Raga et al. 2014), but the risk can be reduced through a combination of mitigation activities and information campaigns (Holle 2016; Antonescu and Cărbunaru 2018). The NOAA NWS "when thunder roars, go indoors" and "turn around, don't drown", slogans are examples of information campaigns used to mitigate lightning and flood deaths (NWS 2019b; https:// www.weather.gov/safety/flood-turn-around-dont-drown).

Riebsame et al. (1986) emphasized the need for societal guidelines that highlight the relative risks from different weather hazards and their impact on population groups. Toward that end, this study examines a large number of weather fatalities sorted by 5-yr age groups. Hazard environments were examined in terms of age-related limitations associated with mobility and perception. Additional details regarding the methodology for this study are provided in section 2 , which is followed by results in section 3 . Section 4 closes with a discussion and concluding remarks.

\section{Method}

The NOAA Storm Data database that is available online (https://ncdc.noaa.gov/stormevents) is a record of storms and other significant weather events occurring within the United States and its territories since January 1950. Fatality information in Storm Data exists before 1996; however, demographic information for those years is missing. Given the focus of this study, the authors used the part of the database from 1996 to 2018. It documents 14434 fatalities for study. Storm Data was also supplemented with surveys compiled from internet news media.

Fatalities were stratified into 5-yr age groups ranging from 0 to $104 \mathrm{yr}$ old. Total fatalities by age group ranged from a maximum of 1149 for the 50-54-yr-old group to a minimum of 8 for the 100-104-yr-old group. Because large variations in sample size existed between age groups, the following normalization process was conducted: 1) the number of people in an age group killed by a hazard listed in Storm Data between 1996 and 2018 was compiled ( $\left.n_{\text {group }}\right) ; 2$ ) for each age group, the total number of people killed by all analyzed hazards was summed $\left(N_{\text {group }}\right) ; 3$ ) each sample described in step 1 was normalized by the summation determined in step 2 . That ratio is expressed as

$$
\text { normalized fatalities }=n_{\text {group }} / N_{\text {group }} .
$$

This method of normalization allows all age groups to be compared in a standardized fashion during the analysis 
of individual hazards. Furthermore, this method better defines which hazards were responsible for the most fatalities in a particular age range. However, this method does not reveal the number of people in an age group who were exposed to a hazard and survived - which is the primary shortcoming of this study and represents an important topic for future analysis.

Deficiencies in Storm Data have been documented by Curran et al. (2000), Ashley and Mote (2005), and Ashley (2007), among others. Those studies note that fatality data were more likely to be accurate in highimpact events such as tornado outbreaks and less accurate for weather events yielding low fatality counts. For example, underreporting of lightning deaths by NWS employees has occurred because of 1) reliance on newspapers, 2) the singular nature of lightning fatalities, and 3) lightning being listed as a secondary cause of death instead of a primary cause. Errors and inconsistencies identified by previous authors warrant caution when using Storm Data for scientific research (Ashley 2007; Gensini and Ashley 2009).

Graphs of normalized fatalities were plotted for each hazard extracted from Storm Data. Hazard graphs that displayed visually identified maxima in normalized fatalities for a specific age range were processed for additional analysis. Those hazards included heat, cold, tropical cyclones, tornadoes, areal and flash flooding, winter weather, lightning, wildfires, rip currents, high surf, and avalanches. Hazards that were associated with small sample sizes or that, after being graphed, lacked a clear signal showing age-group maxima were excluded from further analysis. Hazards excluded included blizzards, debris flows, fog, snow, ice, dust storms, marine winds, straight-line winds, heavy rain, sneaker waves, coastal flooding, tides, tsunamis, and hail. Additional demographic information included in the extended analysis consisted of fatalities with respect to gender, physical location of death, time of year, state and county of occurrence, and circumstances specific to each fatality (if provided in the Storm Data event narrative).

In addition, age-group fatalities for each hazard were spatially analyzed on a $0.35^{\circ}$ latitude $\times 0.35^{\circ}$ longitude grid using a Cassini projection. Fatalities were plotted based on the latitude and longitude centered on the county of occurrence. Gaussian $(3 \times$ 3) lowpass filter smoothing using a sigma value of 0.85 was then applied to the resulting grid. This produced plots that preserved the maximum grid point value surrounded by spatially smooth values that show fatality coverage while simultaneously maintaining readability.
TABLE 2. Total number of fatalities associated with each hazard extracted from NOAA Storm Data, valid over 1996-2018.

\begin{tabular}{lc}
\hline \multicolumn{1}{c}{ Hazard } & Fatalities \\
\hline Heat & 2999 \\
Cold & 616 \\
Winter (snow) & 1072 \\
Flash flooding & 1395 \\
Areal flooding & 521 \\
Lightning & 826 \\
Avalanche & 290 \\
Rip current & 846 \\
High surf & 213 \\
Tornado & 1722 \\
Wildfire & 167 \\
Tropical & 1288 \\
\hline
\end{tabular}

\section{Results}

\section{a. General demographics}

Total fatalities increase from age 0 through $50-54$, after which fatalities fall gradually through age 80-84, and then decline steeply through age 104 (see Table 2 for total fatalities associated with each hazard; see Fig. 1 for total fatalities associated with each age group). Total normalized fatalities for each age group in comparison with the U.S. population shows that younger groups $(<50 \mathrm{yr}$ old $)$ experienced relatively fewer fatalities with respect to their representation within the larger U.S. population. The reverse was true for age groups $\geq 50 \mathrm{yr}$, such that the relative number of fatalities exceeded their representation within the broader U.S. population (Fig. 2).

Normalized fatalities were maximized for age groups less than $10 \mathrm{yr}$ old for tornadoes, flash flooding, and areal flooding; maxima for the 15-19-yr-old group were observed for winter weather, lightning, and rip currents; maxima occurred in the 15-44-yr-old group for avalanche, wildfire, and high surf; and heat, cold, and tropical-cyclone fatalities peaked in age groups $>80 \mathrm{yr}$ old (Fig. 3).

Gender-specific fatality information was assessed by dividing the total number of males killed by a hazard with the total number of females killed - with a male-to-female ratio of less than 1 indicating that more females were killed than males. Figure 4 shows that slightly more females were killed by cold, heat, and tropical cyclones; an equal number of males and females were killed by winter weather; and slightly more males were killed by tornadoes, flash flooding, and areal flooding. Substantially more males, at a ratio of greater than 4 males for each female, were killed by lightning, high surf, wildfires, rip currents, and avalanches. Those hazards in which a larger ratio of females were killed relative to males were maximized in a relative sense for persons $>80 \mathrm{yr}$ old, which is in line with the general U.S. 


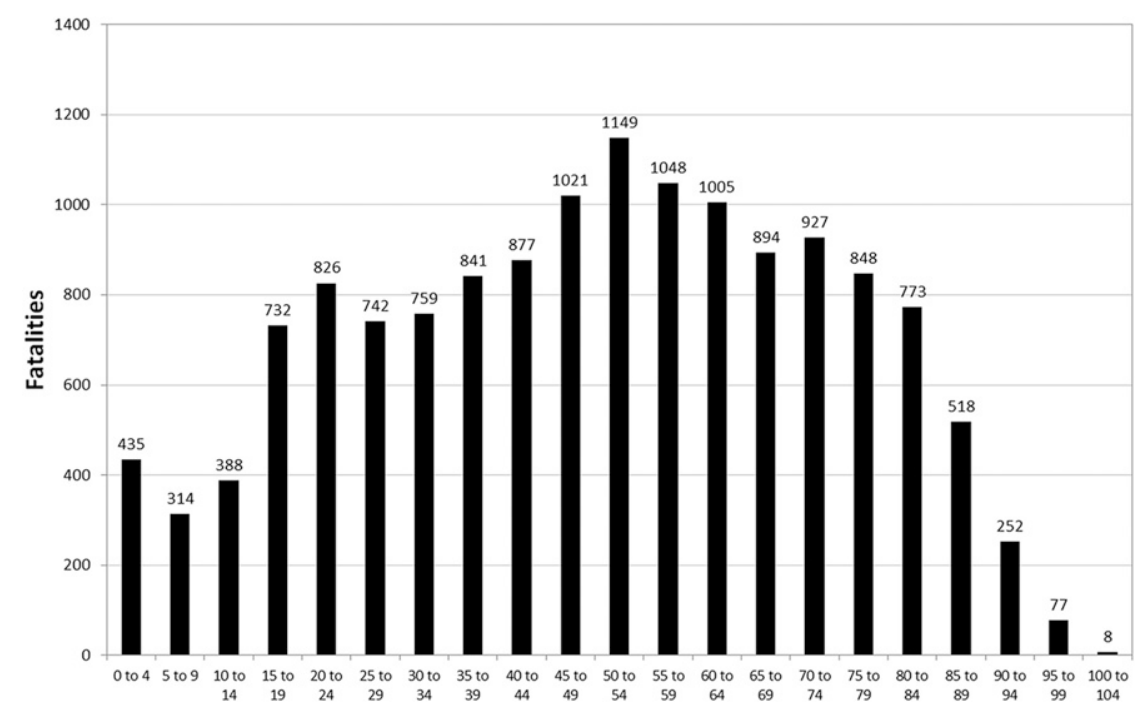

FIG. 1. Total number of weather fatalities for each 5-yr age group analyzed in NOAA Storm Data from 1996 to 2018.

population in which more elderly females exist than elderly males. In contrast, tornadoes and flooding fatalities were skewed slightly toward males, which were maximized for age groups between 5 and $9 \mathrm{yr}$ old. Weather fatalities that were strongly skewed toward males were all maximized between age 15 and 40 .

The location of death (not shown) revealed that age groups $>60$ were more likely to die inside a permanent home structure; age groups $<25$ were more likely to die in the water, in a mobile home, in a vehicle, or on an athletic sports field; while age groups between 25 and 60 were more likely to die on a boat or in the outdoors recreating or working. Analysis of fatalities by time of day (not shown) was not particularly revealing, with the exception of the mid- to late morning period, which was dominated by elderly age groups. Stronger signals emerged in peak fatalities by month (not shown). All elderly age groups showed maxima during the months of July and August, which were months in which heat and tropical-cyclone fatalities were more likely. Age groups $<15$ yr old experienced the greatest number of fatalities during the months of April, May, June, July, and September. Age groups from late teens through middle age did not show strongly amplified signals in any month except for December, which may be associated with increased vulnerabilities due to winter weather activities (such as driving, skiing, snowboarding, and snowmobiling).

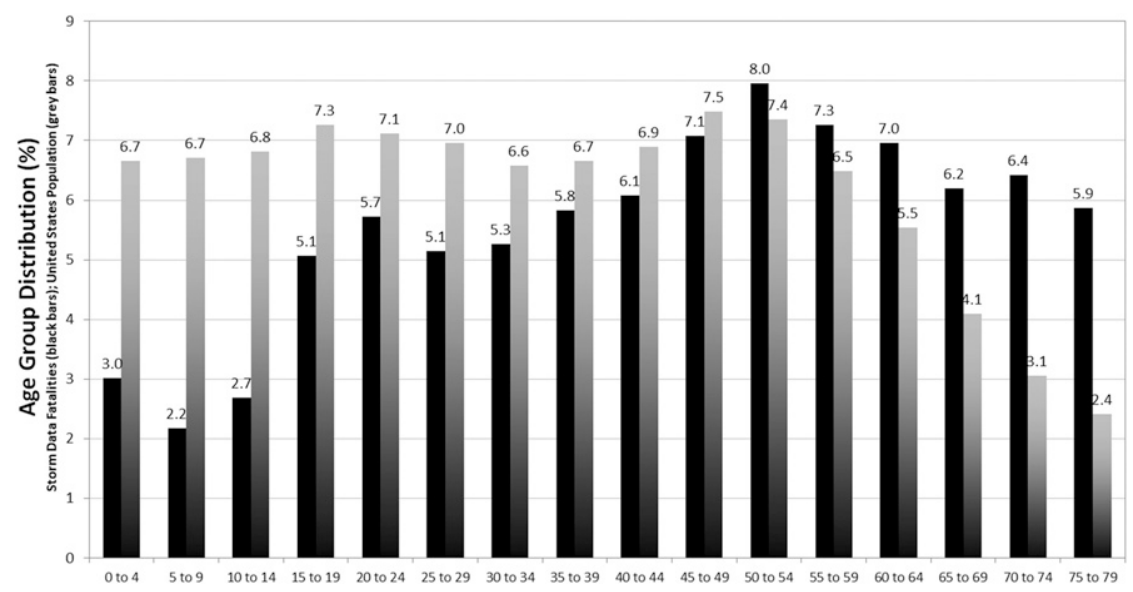

FIG. 2. Distribution of weather fatalities by age group represented in Storm Data from 1996 to 2018 (black bars) compared with the same age groups in the U.S. population normalized by the total U.S. population for 2017 (gray bars). Numerical values above each bar represent the percentage of the total population within a particular 5-yr age group. The U.S. population estimate is provided by the U.S. Census Bureau (https://www.census.gov/). 


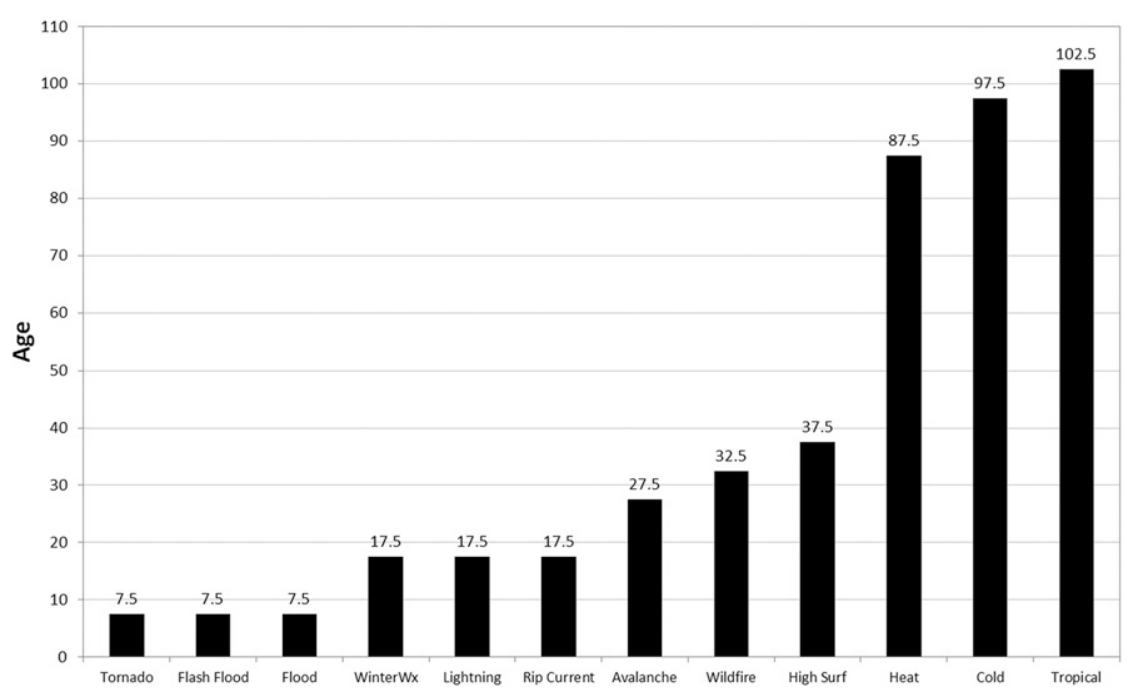

FIG. 3. Ages in which individual weather hazards analyzed in the 1996-2018 dataset were maximized. Note that the sample size for the 102.5 -yr age bin is 8 .

Different states were associated with maxima in normalized fatalities for different age groups (not shown). Mountainous states, or those with ocean coastlines, featured fatality maxima in the teen through middle-age groups. Those states included Wyoming, California, Washington, Florida, and Alaska. States including Illinois, Missouri, and Pennsylvania displayed fatality peaks in elderly age group categories. Texas, Oklahoma, and Arkansas showed peaks in fatalities for age groups $<10$ yr old. Louisiana showed a particularly distinct fatality maximum in age groups $>80 \mathrm{yr}$ old.

\section{b. Heat}

Heat deaths displayed a bimodal age distribution (Fig. 5), with maxima in normalized fatalities occurring in the very young (age $0-4$ ) and the very old (age 75-104). The maximum for the $0-4 \mathrm{yr}$ group appears particularly anomalous, as it is 6.8 times greater than the adjacent 5-9-yr-old age group. A minimum occurs between 5 and $24 \mathrm{yr}$, with a near-linear increase in fatalities occurring through age 50 . In addition, the 23 -yr trend in heat-related fatalities gradually rose above the $23-y r$ mean for the $0-4$ yr group, while fatalities in the 75-104 yr group did not display a definitive trend (Fig. 6).

[Note that Figs. 7-10 give a spatial analysis of fatalities by hazard and age group on a $0.35^{\circ}$ latitude $\times 0.35^{\circ}$ longitude grid. The data are derived from NOAA Storm Data and cover the period of 1996-2018. The series of figures covers different combinations of weather-related hazardous situations and age groups that are of particular interest. The figures will be discussed in more detail in the relevant sections below.]
Heat deaths for the $0-4$-yr-old age group were most frequently observed in Texas $(28 \%)$, followed by Illinois (9\%), Arkansas (7\%), and Alabama at 5\% (Fig. 7a). Furthermore, $86 \%$ of the heat deaths in the very young group were due to children either being left inside a vehicle by an adult caretaker or very young children entering a vehicle and becoming entrapped. In both cases, those children were unable to escape the vehicle as inner-vehicle temperatures led to heat stroke.

Heat deaths occurring among the elderly (age 75-104) were maximized in Pennsylvania (19\%), Illinois (13\%), Missouri (12\%), Nevada (12\%), and Texas (12\%). Furthermore, $16 \%$ of all elderly heat fatalities occurred within the city of Philadelphia, Pennsylvania; $12 \%$ occurred in Las Vegas, Nevada; $10 \%$ in Chicago, Illinois; and $5 \%$ in Saint Louis, Missouri (Fig. 7b). In comparison, heat deaths in the very young primarily occurred inside vehicles, while $76 \%$ of heat deaths in the elderly occurred within a home setting, often while the victim was completely alone (Klinenberg 2002).

Changnon et al. (1996) found that urban areas produced meteorological conditions that made them particularly vulnerable to high numbers of heatrelated fatalities. In particular, the risk of a fatal outcome was found to be greater for the urban elderly because those in low-income areas usually did not have air conditioning or could not afford to operate a unit during a heat wave, and the elderly also feared that opening windows for ventilation at night would increase the risk of a home invasion. As a result, solitary elderly victims have often been found dead within stifling hot apartments (Palecki et al. 2001). Hot temperatures 


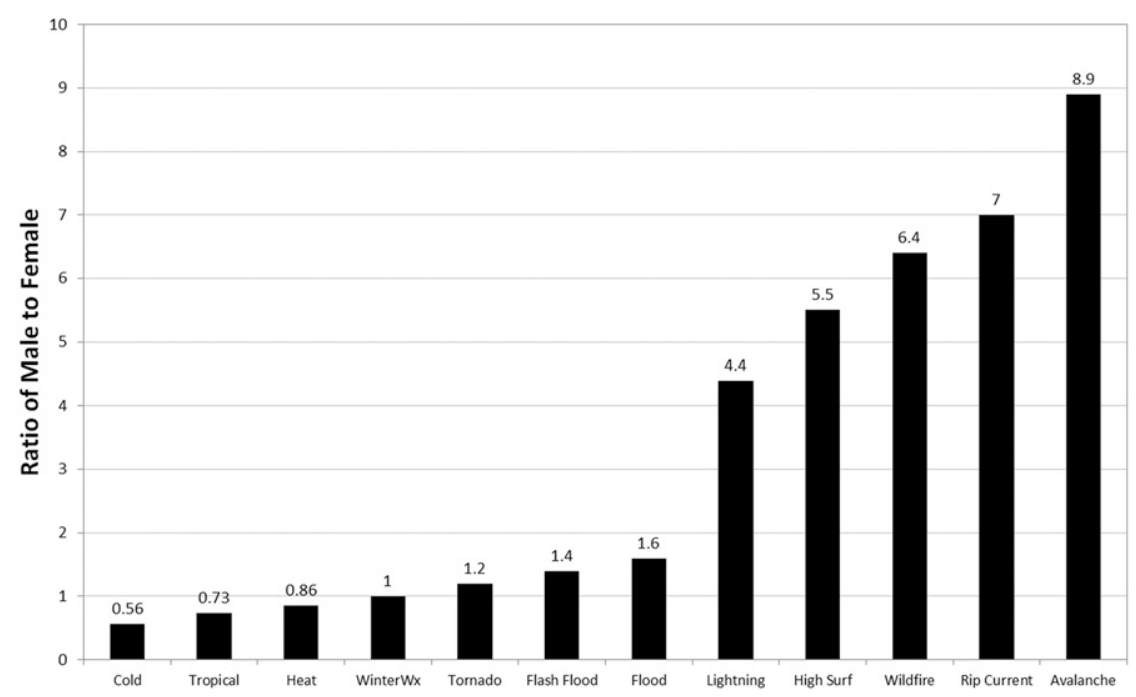

FIG. 4. Ratio of male to female fatalities for weather hazards analyzed from 1996 to 2018. A value of less than 1 indicates more females were killed than males.

are common over southern portions of the United States but occur more infrequently over northern urban areas, which may partially explain why cities such as Philadelphia and Chicago are more prone to elderly heat fatalities (Kalkstein et al. 1996). However, these northern cities are taking steps to actively engage their most vulnerable citizens (see Table 3) and ensure that they have the support necessary to survive a heat wave (City of Chicago 2019; Shoyinka 2019).

\section{c. Cold}

Cold-weather fatalities peaked in the elderly population, particularly for groups $\geq 85 \mathrm{yr}$ (Fig. 11). Within that age group, $63 \%$ of the fatalities were female, which is consistent with the elderly gender distribution within the general U.S. population. Not surprisingly, cold-weather deaths were maximized during the winter months of December (20\%), January (46\%), and February (27\%). Illinois led the nation in these kind of deaths at $32 \%$ (see Fig. 7c), followed by Wisconsin (15\%) and Pennsylvania $(11 \%)$. In addition, the Chicago metropolitan area was particularly prone to cold-weather fatalities in the elderly group, with $22 \%$ of the analyzed deaths occurring within that city.

Twenty-six percent of cold-weather fatalities among the elderly occurred within a home setting. However,

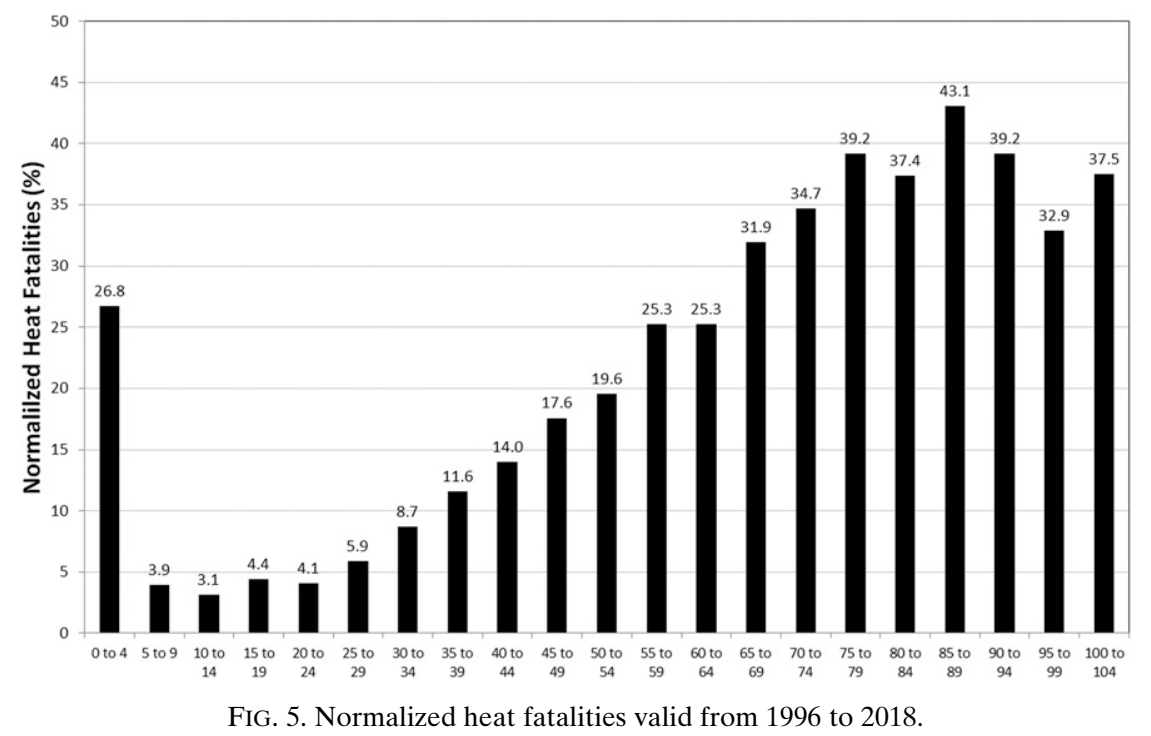



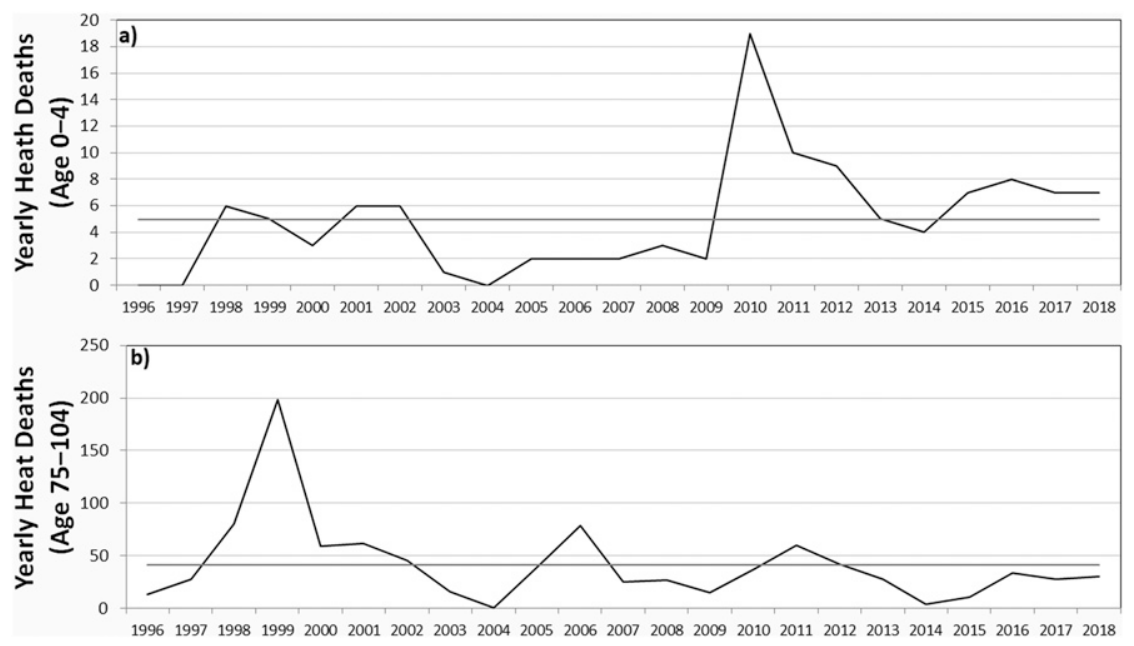

FIG. 6. The yearly change in heat fatalities valid from 1996 to 2018 for (a) the $0-4$-yr-old age group and (b) the 75-104-yr-old age group. The horizontal line is the 23-yr mean.

a significant number of elderly succumbed to the cold by either walking away from their home $(30 \%)$ or falling down outside and failing to get up (23\%). An additional $9 \%$ of deaths occurred when an elderly person locked themselves out of their home. Rodriguez (2014) notes that urban-dwelling elderly are particularly at risk to a fatal cold weather outcome because they tend to have fewer family members around who can assist in making sure their heating needs are met.

\section{d. Winter weather}

Winter weather hazards associated with accumulating snow produced fatal outcomes that were maximized in younger populations centered on the 15-19-yr-old age group (Fig. 12), with normalized fatalities gradually a)

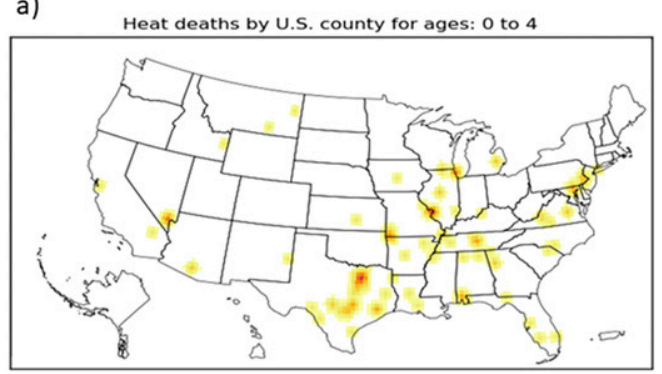

c)

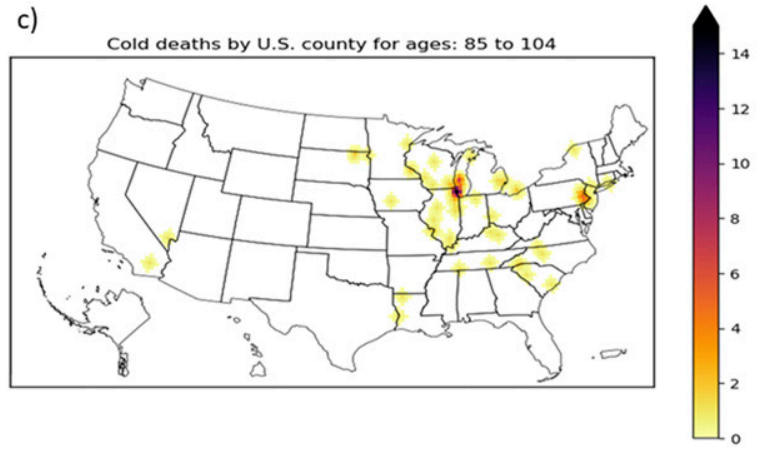

b)

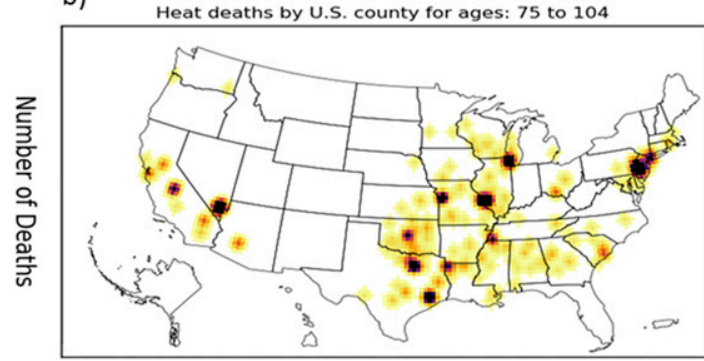

ths by U.S. county for ages: 75 to 104

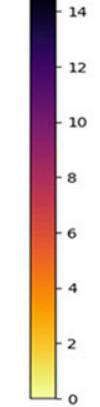

d)

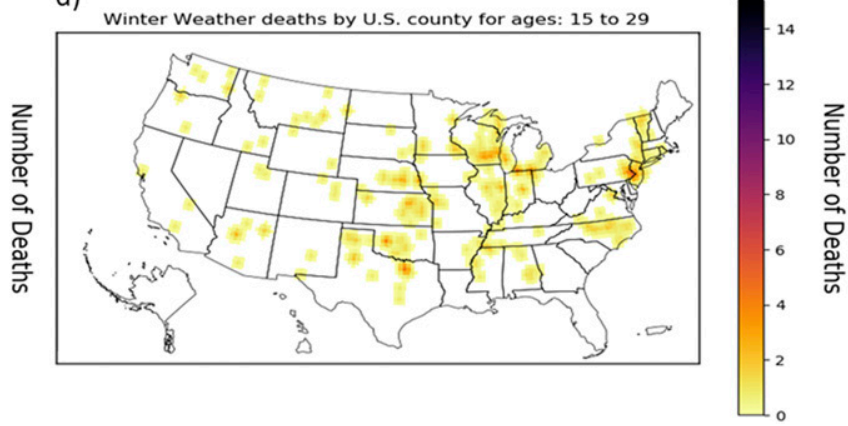

FIG. 7. Spatial analysis of fatalities in a $0.35^{\circ}$ latitude $\times 0.35^{\circ}$ longitude grid derived from NOAA Storm Data, valid over $1996-2018$ for (a) heat deaths for the 0-4-yr-old age group, (b) heat deaths for the 75-104-yr-old age group, (c) cold deaths for the 85-104-yr-old age group, and (d) winter weather deaths related to snow for the 15-29-yr-old age group. 
a)

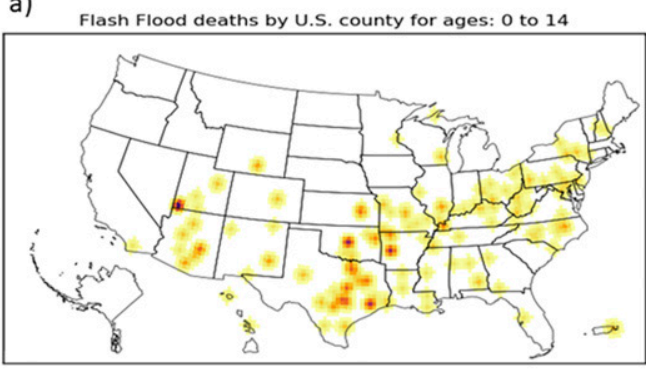

c)

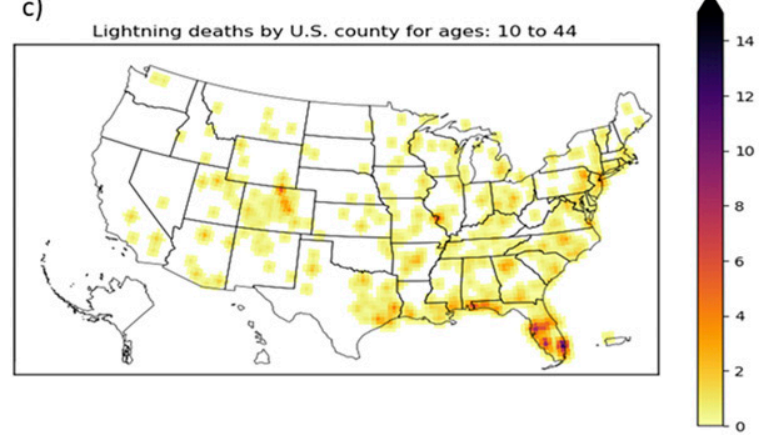

b)

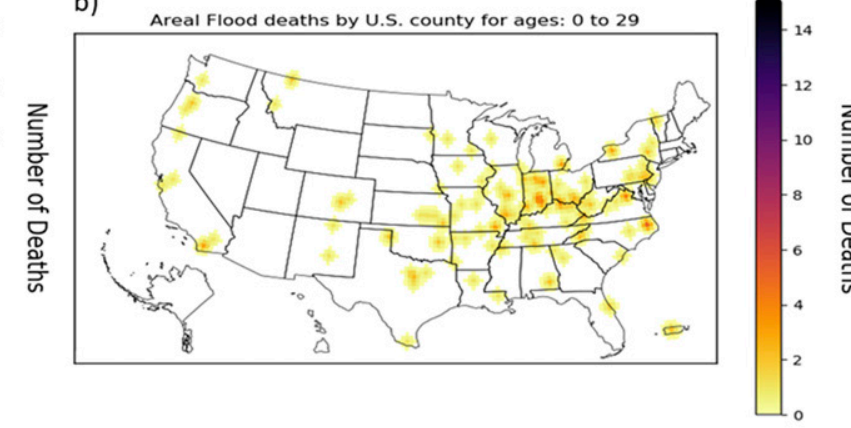

d)

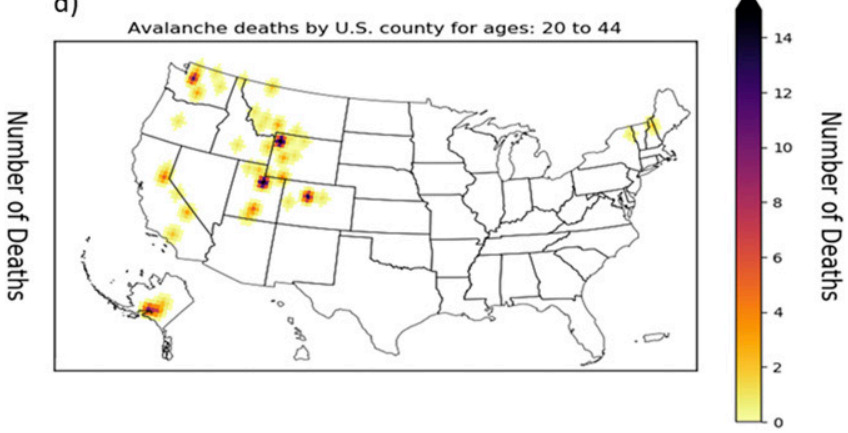

FIG. 8. As in Fig. 7, but for (a) flash-flood deaths for the 0-14-yr-old age group, (b) areal-flood deaths for the 0-29-yr-old age group, (c) lightning deaths for the 10-44-yr-old age group, and (d) avalanche deaths for the 20-44-yr-old age group.

decreasing through middle and elderly age. Most fatalities in the age group ranging from the midteens through twenties occurred inside a vehicle $(86 \%)$. And not unexpectedly, fatal winter weather events were most likely during the months of December (29\%), January (28\%), and February (22\%). In Wisconsin, $10 \%$ of the fatalities were observed, with Texas and Indiana experiencing $7 \%$, respectively, followed by $5 \%$ occurring in California, North Carolina, and Nebraska, respectively (Fig. 7d).

\section{e. Flooding}

Normalized flash- and areal-flood fatalities not associated with tropical cyclones peaked in the 5-9-yr-old age group (Fig. 13), but the peak was more pronounced for flash flooding $(25 \%)$ than for areal flooding $(7 \%)$. Broadening the flash-flood fatality analysis to the $0-14 \mathrm{yr}$ group reveals that deaths occurred mainly during the spring and summer when thunderstorms were most probable. Conversely, areal-flood fatalities in the 0 $29 \mathrm{yr}$ group were maximized during the late winter into spring. The states experiencing the greatest number of flash-flood fatalities in the $0-14$ yr group were Texas ( $24 \%$ ), followed by Utah, Oklahoma, Arkansas, and Arizona at $7 \%$, respectively (Fig. 8a). On the other hand, areal-flood fatalities in the $0-29 \mathrm{yr}$ group were most frequently observed in Indiana (13\%), Kentucky
(6\%), Illinois (6\%); Texas, Missouri, North Carolina, Ohio, and Virginia at 5\%, respectively; and New York, Tennessee, and Pennsylvania at 4\%, respectively (Fig. 8b).

A large number of people from 0 to $14 \mathrm{yr}$ in age died in flooded drainages, ditches, and culverts; $42 \%$ of those deaths resulted from children playing next to or within or trying to cross a flooded drainage system. Those children fell into fast-flowing water and were swept downstream and drowned, sometimes within drainage pipes. A 2008 World Health Organization (Peden et al. 2008) study highlights the attractive nature water poses to children, particularly those $<5 \mathrm{yr}$ old. Unfortunately, this very young age group is characterized by an underdeveloped perception of the threat that fast flowing water poses and may lack the physical ability to exit flood waters.

Otherwise, flash- and areal-flood deaths were most likely to occur within a vehicle. For the $0-14 \mathrm{yr}$ flashflood group, $48 \%$ died within a vehicle, which was lower than the $0-29 \mathrm{yr}$ areal-flood group (59\%). The authors speculate that for those persons too young to drive, their fatal outcomes were a direct result of poor threat perception on the part of older caretakers.

\section{f. Lightning}

Normalized lightning fatalities rise $841 \%$ from a minimum in the $0-4$-yr-old age group to a maximum centered on the 15-19 yr group (Fig. 14). Fatalities 
a)

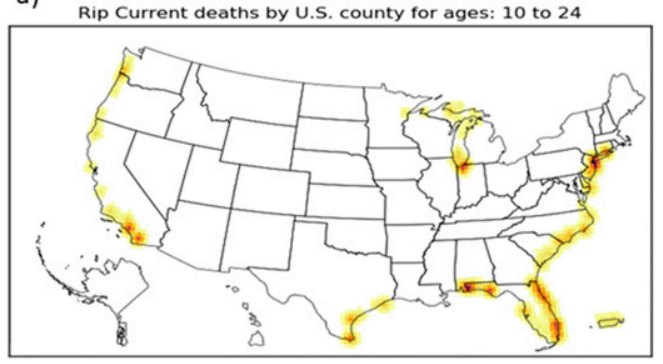

c)

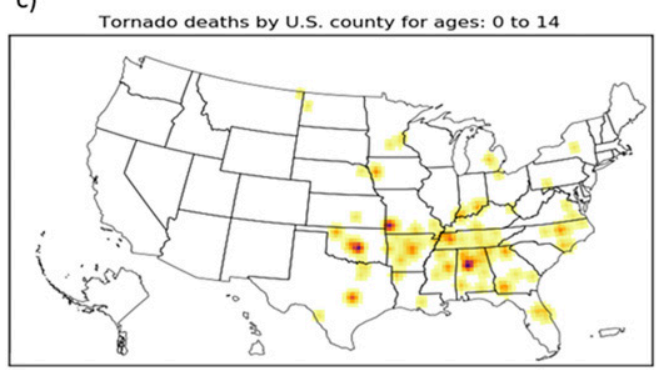

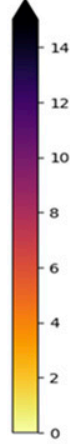

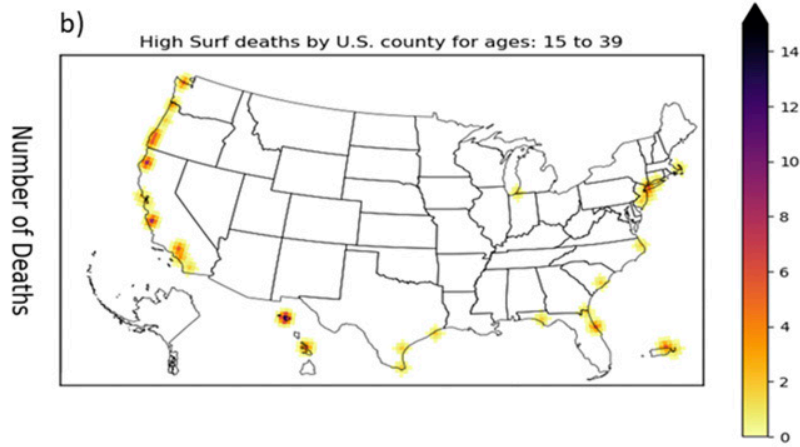

(d)

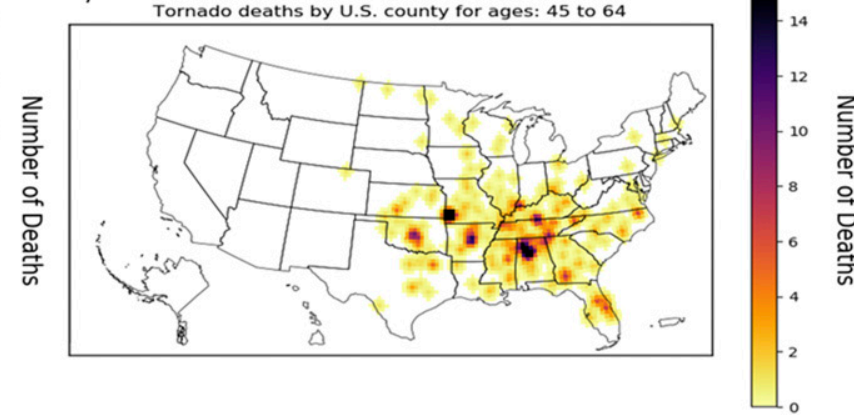

FIG. 9. As in Fig. 7, but for (a) rip-current deaths for the 10-24-yr-old age group, (b) high-surf deaths for the 15-39-yr-old age group, (c) tornado deaths for the 0-14-yr-old age group, and (d) tornado deaths for the 45-64-yr-old age group.

remain elevated near $10 \%$ through middle age and then fall by a factor of 2 through the elderly age groups. Males made up $82 \%$ of the lightning fatalities that were examined, and the most likely setting for a fatal event was an outdoor work environment (31\%), followed by people walking or running outside $(17 \%)$, people recreating at a beach $(13 \%)$, and people hiking or climbing (10\%). Over $70 \%$ of lightning fatalities were observed during the months of June, July, and August. Florida by a wide margin experienced the most deadly strikes (19\%), followed by Texas and Colorado at $7 \%$, respectively (Fig. $8 \mathrm{c}$ ). In addition, the $23-y r$ trend in lightning fatalities showed that public education efforts (https://www.weather.gov/safety/lightning)

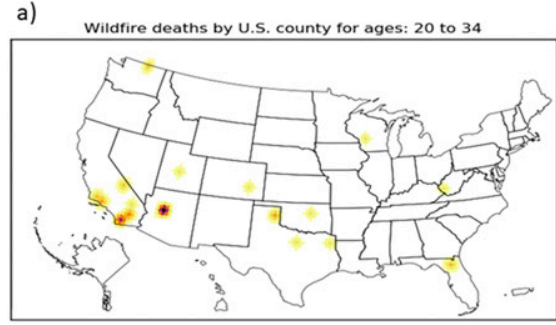

c)

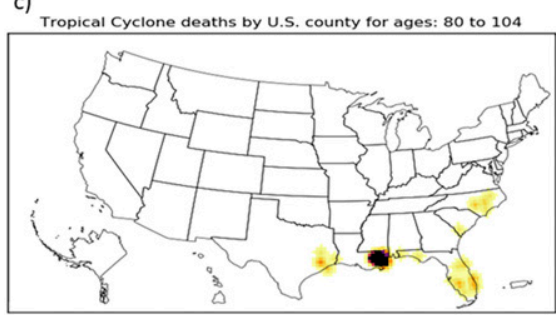

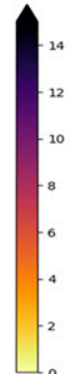

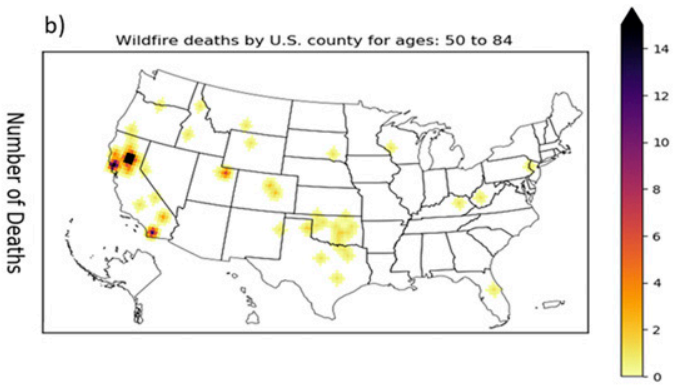

FIG. 10. As in Fig. 7, but for (a) wildfire deaths for the 20-34-yr-old age group, (b) wildfire deaths for the 50-84-yr-old age group, and (c) tropical-cyclone fatalities for the 80-104-yr-old age group. Wildfire fatalities include the 2017 and 2018 deadly northern California wildfire events. 
TABLE 3. Procedures initiated by the cities of Philadelphia and Chicago to assist vulnerable populations during heat waves (City of Chicago 2019; Shoyinka 2019).

\begin{tabular}{cc}
\hline \hline City & \multicolumn{1}{c}{ Procedure } \\
\hline Philadelphia & Heat Health Emergency System: \\
& Employs a special helpline number; \\
& operates cooling centers; dispatches \\
mobile heat health teams; and delays & residential utility shutoffs during heat \\
emergencies & Code Red System: Aids the homeless \\
population during heat emergencies \\
- Extreme Weather Notification: Utilizes \\
phone text and computer e-mail tech- \\
nology to provide weather information \\
to those with special needs \\
- Heat Emergency Mobilization: Cooling \\
centers are set up for vulnerable \\
populations; check up on individuals \\
with special heat-related needs; conduct \\
studies on current and possible future \\
vulnerabilities related to inner-city heat \\
events
\end{tabular}

by the weather enterprise, in addition to other initiatives such as community siren systems, may be yielding positive results-fatalities ranged from 25 to 40 deaths per year during the 1996-2003 period, and decreased to $10-25$ deaths per year during the 2011-18 period (Fig. 15).

\section{g. Avalanche}

Similar to the case for flooding, winter weather, and lightning fatalities, avalanche deaths disproportionately affected younger age groups and showed virtually no impact on elderly groups. People from age 0 to 14 experienced few normalized fatalities (Fig. 16), followed by a dramatic upward spike to a maximum of slightly more than $6 \%$ centered on the 25-29-yr-old group. Normalized fatalities remained elevated through age 44 , and then fell to zero by age 70 .

Additional demographic analysis revealed that roughly nine males were killed by an avalanche for every female killed. In addition, fatalities were maximized during the months of December (20\%), January (24\%), February $(18 \%)$, and March (21\%). Colorado led the nation in avalanche fatalities at $25 \%$ (Fig. $8 \mathrm{~d}$ ), followed by Utah (18\%), Alaska (16\%), Wyoming (14\%), and Washington $(10 \%)$. Circumstances yielding a fatal avalanche event included snowmobiling (38\%), skiing (32\%), and snowboarding (13\%).

\section{h. Surfzone}

Rip currents were responsible for $15 \%$ of $10-14$-yr-old fatalities and $20 \%$ for the 15-19-yr-old group (Fig. 17). Thereafter, rip-current fatalities gradually decreased to values $<1 \%$ for age groups $\geq 60 \mathrm{yr}$. In contrast, normalized fatalities were lower for all age groups for high surf-with a broad peak in normalized fatalities occurring in the $15-39$-yr-old group that ranged from $1.9 \%$ to $3.1 \%$. Additional analysis of fatalities by gender showed that males composed over $87 \%$ of rip-current fatalities and $85 \%$ of high-surf deaths. The large disparity in male deaths relative to females deserves further investigation.

The circumstances leading to fatal rip-current outcomes were associated with persons swimming (59\%), followed by people playing in the surfzone $(14 \%)$ and people attempting to rescue others in the water $(12 \%)$. Figure 18 also indicates that rip-current fatalities trended above their 23-yr mean, though the reasons for that

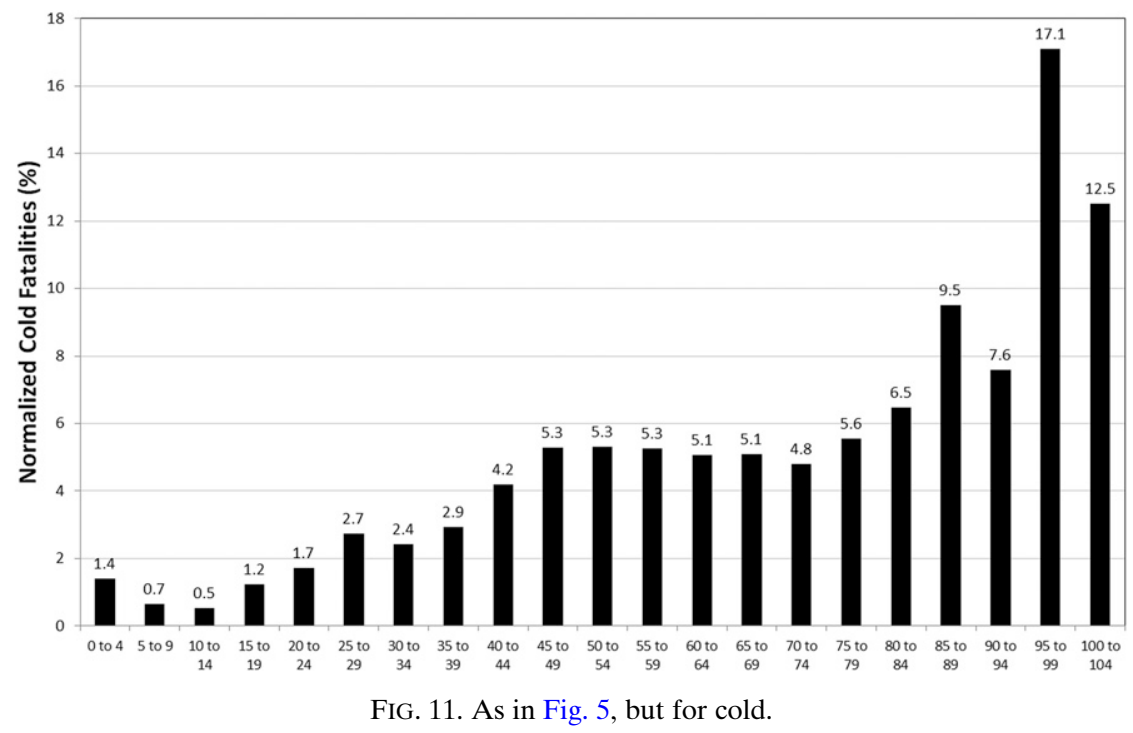




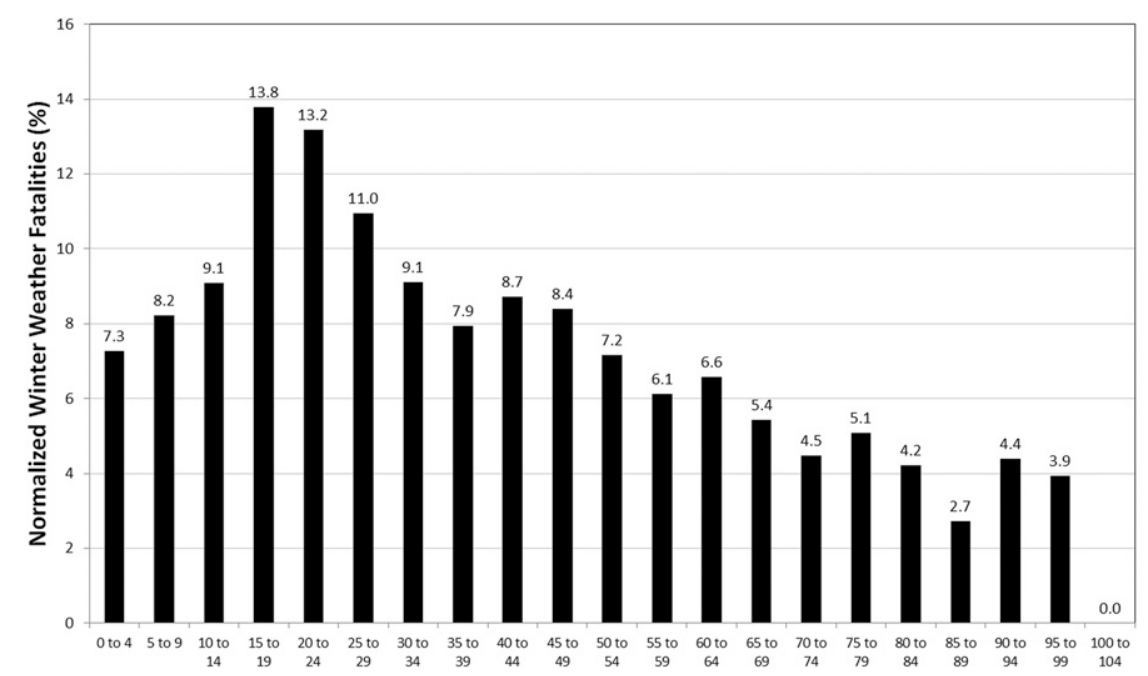

FIG. 12. As in Fig. 5, but for winter weather.

trend are not immediately clear. On the other hand, high-surf fatalities were most likely when someone standing outside of the water was swept into the ocean by a large wave $(45 \%)$, followed by capsizing boats $(15 \%)$, and then surfers who were pulled under water by a wave $(11 \%)$.

Seasonal differences were observed between the two surfzone hazards, with rip-current fatalities more likely to occur during June (17\%), July (21\%), and August $(18 \%)$, while high-surf fatalities were more likely during cooler months such as January (18\%), March (10\%), October (10\%), and December $(10 \%)$. Those seasonal differences may be due to 1) summer months being associated with warmer and calmer ocean waters and pleasant beach weather that encourages swimming and subsequently exposes people to rip currents, and 2) the cool season is the time of year when strong extratropical cyclones move across the ocean, leading to both longperiod and short-period waves supportive of fatal high-surf conditions. These seasonal differences were partially reflected in the geographic distribution of ripcurrent and high-surf fatalities (see Figs. 9a,b). For instance, $30 \%$ of rip-current deaths occurred in Florida, followed by California (10\%), New York $(8 \%)$, and New Jersey and Texas at $7 \%$, respectively. On the other hand, Florida had a much lower percentage of high-surf fatalities (5\%)-instead, Hawaii led the nation in highsurf deaths at $20 \%$, California was second at $18 \%$, followed by Guam $(13 \%)$, Puerto Rico $(12 \%)$, and Oregon (9\%).

Inspection of internet media sources also indicates that many rip-current victims lived outside of a region with a beach, while high-surf victims lived close to a coastal location. This makes intuitive sense-summer
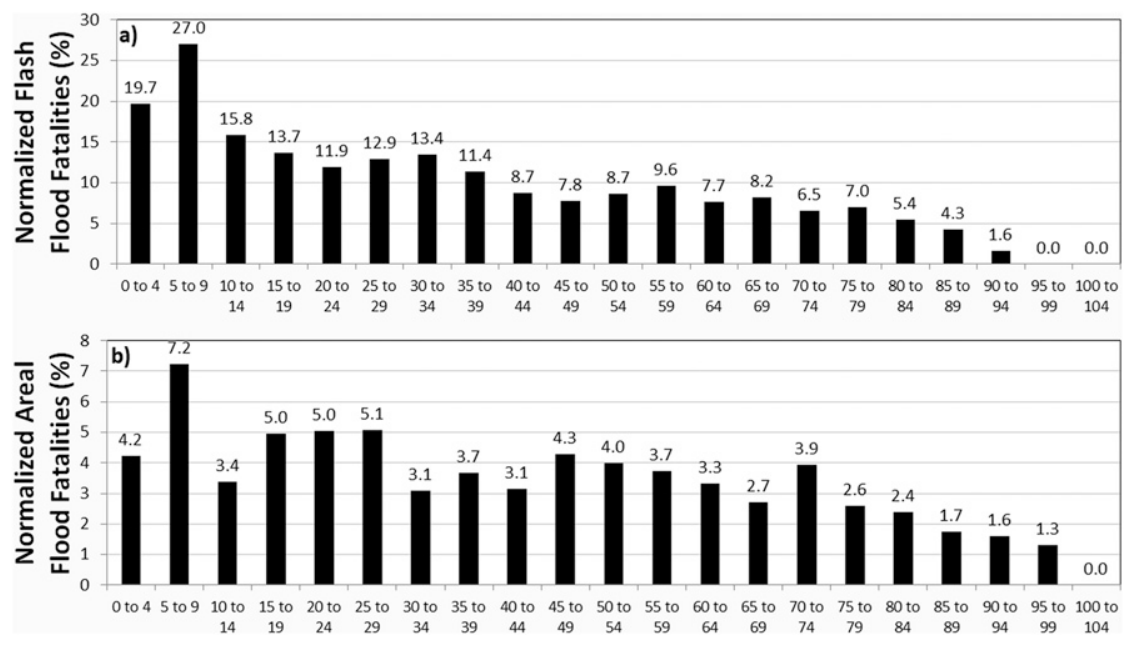

FIG. 13. As in Fig. 5, but for (a) flash flooding and (b) areal flooding. 


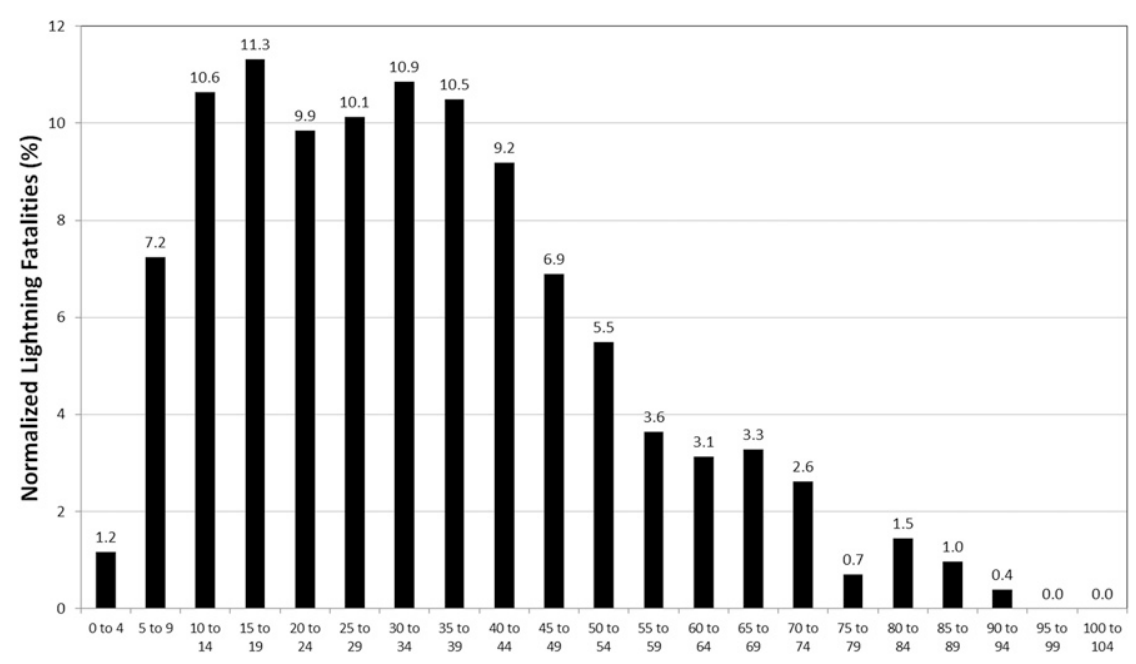

FIG. 14. As in Fig. 5, but for lightning.

vacationers who live inland travel to the beach and may not be familiar with rip-current threats, while so-called locals who live near a beach would be more likely to visit the coast during cooler stormier months of the year and would be more likely to experience conditions of high surf.

\section{i. Tornadoes}

From a normalized perspective, tornado fatalities peaked in the 5-9-yr-old age group $(17.8 \%)$, then fell by a factor of 2.3 to a minimum value of $7.6 \%$ in the 15-19 yr group, before rising again and remaining elevated through middle-aged groups (Fig. 19). Further detailed analysis of the very young and middle-aged maxima reveal that both groups were more likely to be killed by a tornado during the afternoon or evening in the months of April and May (Fig. 20). Those killed by nocturnal tornadoes were more likely to succumb during February and November, which are months consistent with the November-April peak in killer nocturnal tornadoes presented by Ashley (2007).

For persons $<15 \mathrm{yr}$ old, nocturnal fatalities were more likely to occur within a trailer home, while permanent home structures were the most likely setting for a fatal outcome during the afternoon and evening. Analysis of tornado pathlength and width revealed that afternoon tornadoes were $15 \mathrm{~km}$ longer and $0.98 \mathrm{~km}$ larger, respectively, during the afternoon relative to nocturnal events. From those results, we deduce that afternoon tornadoes had greater destructive potential (Brooks 2004), and thus permanent homes were more vulnerable to damage yielding fatalities. Similar results were observed in middle-age groups. In addition, persons $>15 \mathrm{yr}$ were slightly more vulnerable to tornado fatalities

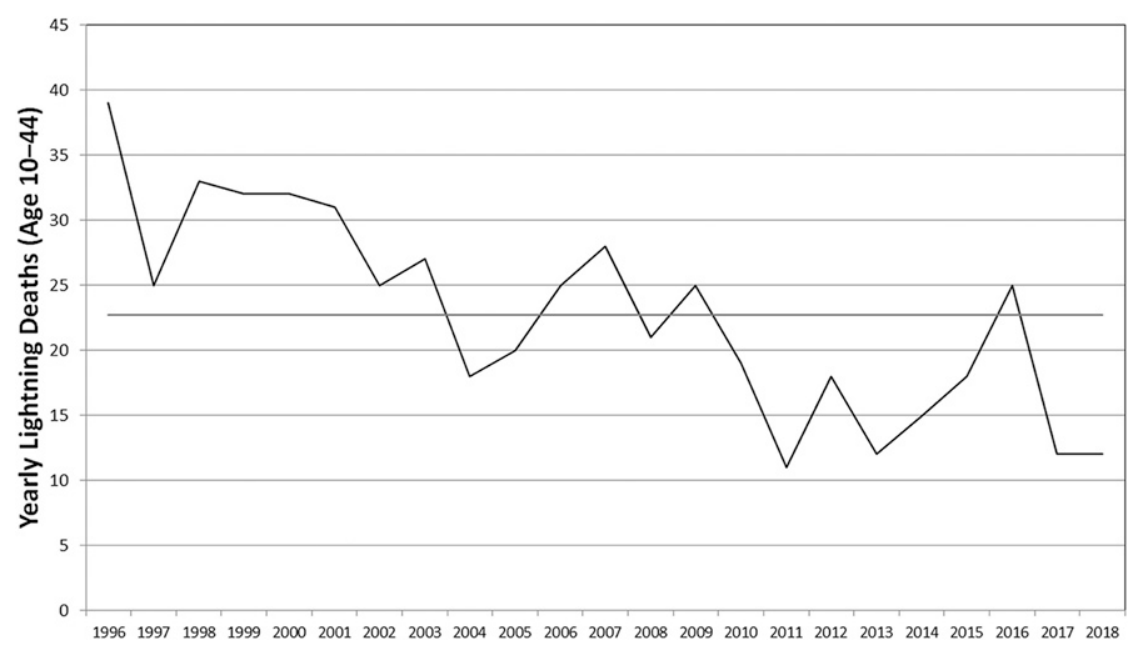

FIG. 15. As in Fig. 6, but for lightning for age 10-44. 


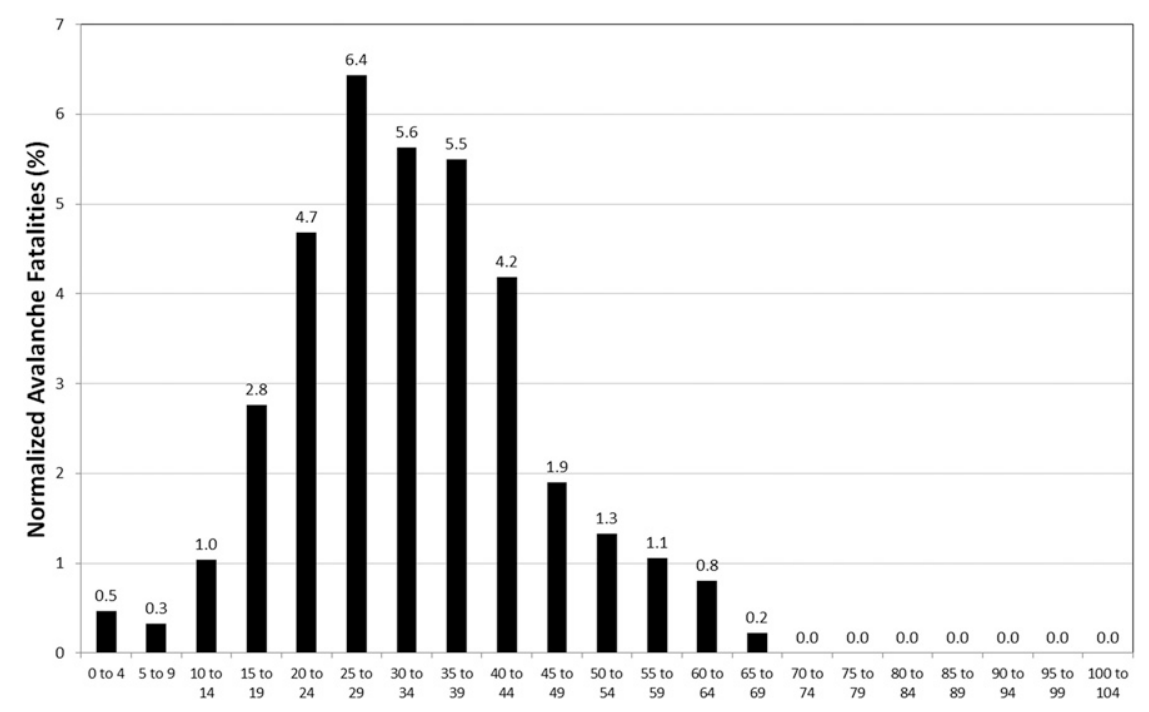

FIG. 16. As in Fig. 5, but for avalanches.

occurring within a vehicle than were persons $<15$ yr. On the other hand, $4 \%$ of the fatalities in the younger age group occurred in a school setting during the afternoon and early evening hours, whereas no fatalities in older age groups were in a school.

Normalized fatalities for those $<15 \mathrm{yr}$ old were maximized during the afternoon and evening in the states of Alabama, Oklahoma, Arkansas, Missouri, Texas, and Tennessee; while fatalities at night were more likely in Georgia, Florida, Indiana, and Arkansas. Older age groups between 45 and $64 \mathrm{yr}$ were more prone to killer tornadoes in the afternoon in Alabama and Missouri but were slightly less prone relative to the very young in Oklahoma. Similar to the case for the very young, Florida, Georgia, and Indiana displayed the greatest threat to older persons during the night (reference Figs. 9c and 9d for a spatial analysis of tornado fatalities).

\section{j. Wildfires}

Similar to heat deaths, normalized wildfire fatalities were bimodal (Fig. 21), with maxima observed in both

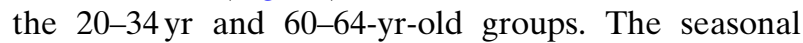
distribution of deaths was also bimodal-one occurring in the spring associated with Great Plains grassland firestorms (Lindley et al. 2014) and a second in the fall occurring with strong offshore winds over California (Raphael 2003; Jones et al. 2010; Nauslar et al. 2018; Mass and Ovens 2019). Over $40 \%$ of wildfire fatalities in both the young and older group occurred in California, followed by Arizona at 33\% for the 20-34 yr group, and $13 \%$ occurring in Texas and Oklahoma, respectively, for
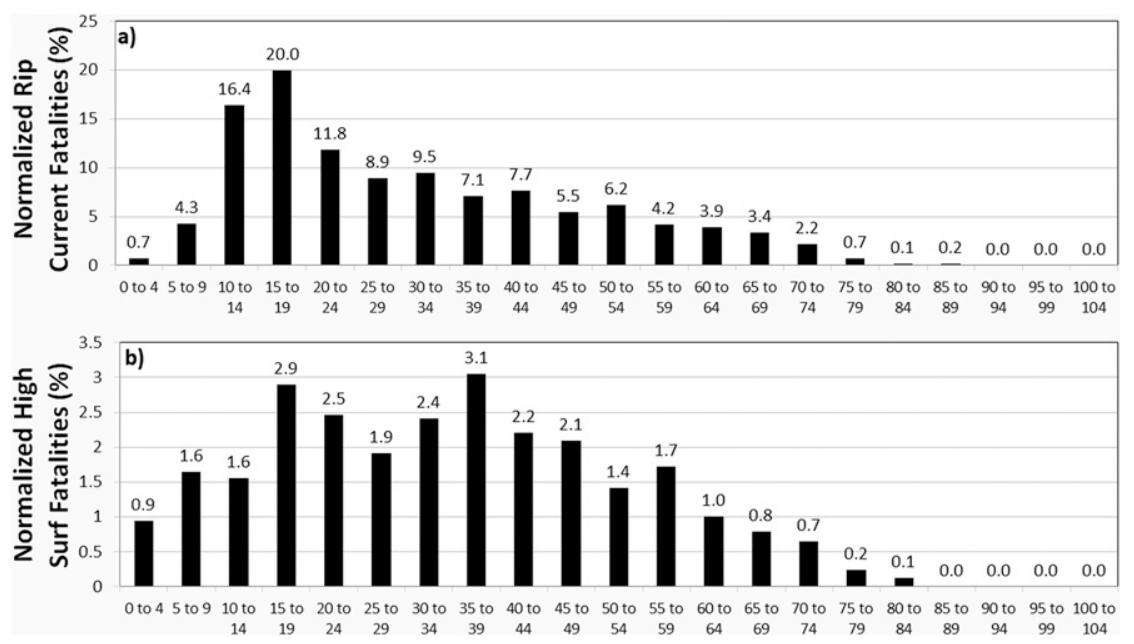

FIG. 17. As in Fig. 5, but for (a) rip currents and (b) high surf. 


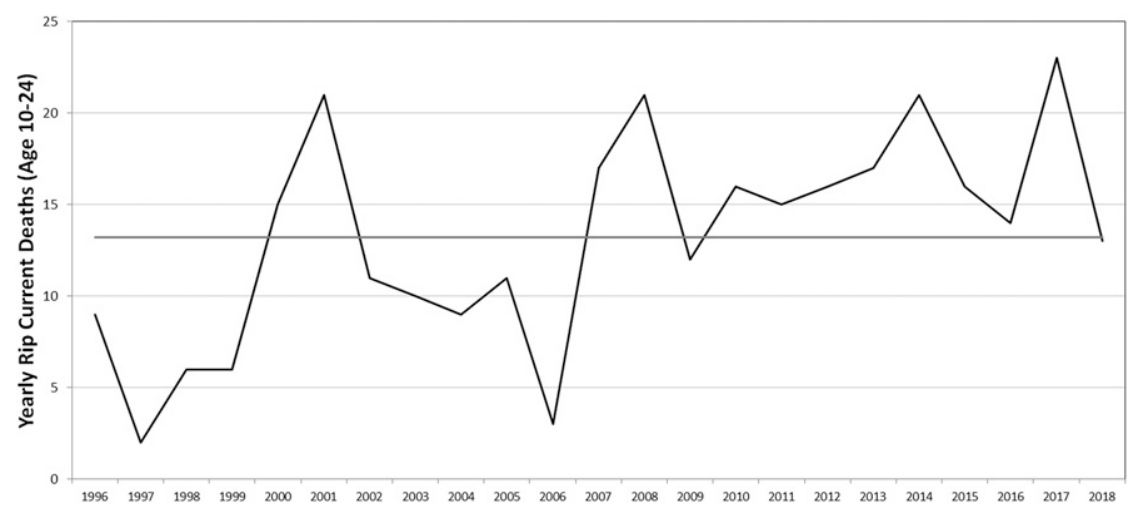

FIG. 18. As in Fig. 6, but for rip currents for age 10-24.

the older group (Figs. 10a,b). In addition, a majority of fatalities in both the young and old age groups occurred outdoors ( $76 \%$ and $47 \%$, respectively); however, more elderly died in their homes $(25 \%)$ than occurred in the younger age group ( $8 \%)$.

The elderly population experienced large numbers of fatalities during the 2017 and 2018 California wildfire seasons (Fig. 21). The Paradise and North Bay (California) wildfires yielded fatalities in the elderly that were roughly twice as high in number as the historical record, with 71 out of a total of 105 fatalities, or $68 \%$, occurring between the ages of 65 and 89 . In addition, the fatality numbers from the Paradise and North Bay events were much larger than similar offshore wind events, such as one in Southern California during December 2017. In that offshore event, one that was arguably one of the more extreme Santa Ana events, only one wildland firefighter fatality was observed. Refer to Table 4 for a list of ingredients characterizing the Paradise and North Bay fatal wildfire events.
Both the Northern and Southern California events were meteorologically similar, characterized by downslope mountain-wave windstorms (Colman and Dierking 1992) that yielded strong gusty winds at the surface. Those winds combined with climatologically low relative humidity values and an abundance of very dry fuels that favored fast moving fires that posed an urgent threat to life and property. However, key socioeconomic factors were different. For instance, the median age in Paradise was between 50 and $52 \mathrm{yr}$ old, which was nearly $15 \mathrm{yr}$ older than the median age for people in the state of California-and much older than for the communities affected by the Southern California Santa Ana event, which ranged from 36 to $41 \mathrm{yr}$. This suggests that older communities may be more vulnerable to extreme wildfire behavior-particularly older communities embedded within the urban-wildland interface (Stein et al. 2013).

Circumstances contributing toward elderly deaths during the Paradise wildfire were in many cases related

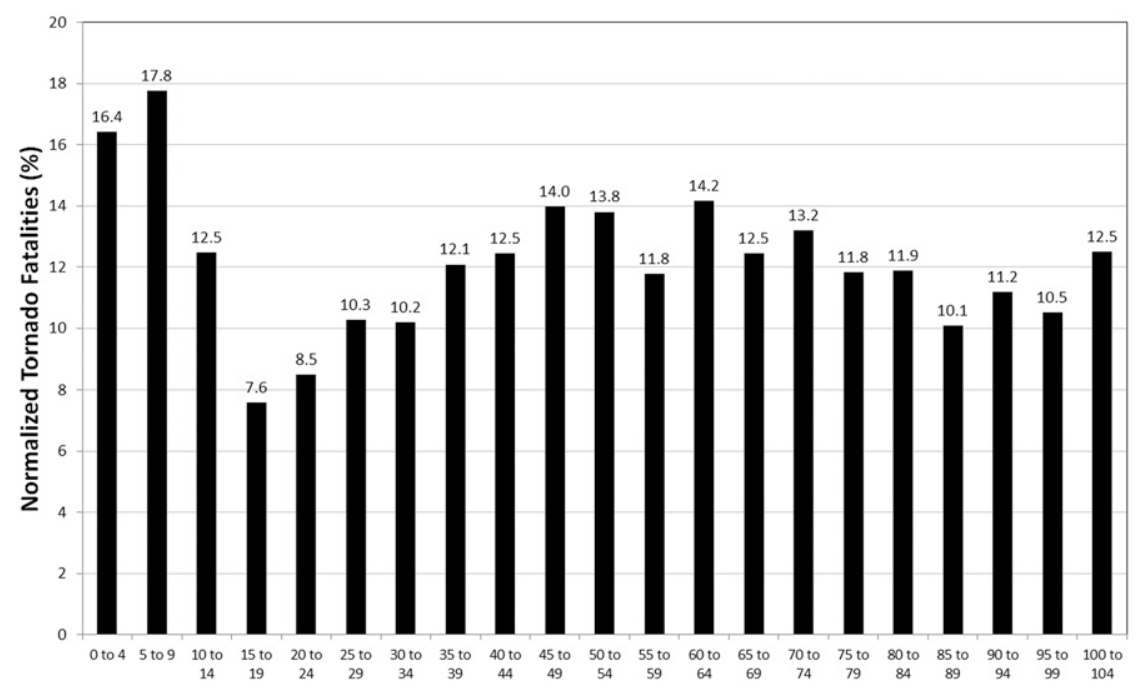

FIG. 19. As in Fig. 5, but for tornadoes. 


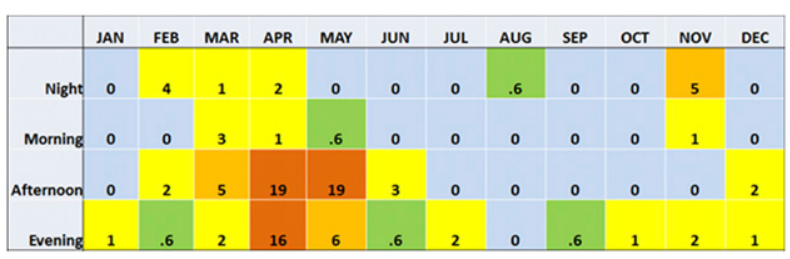

FIG. 20. Percent distribution of tornado fatalities for time of day and month for the 0-14-yr-old age group valid from 1996 to 2018. Night is defined as from midnight to 0559 local time; morning is from 0600 to 1159 local time; afternoon is from noon to 1759 local time; and evening is from 1800 to 2359 local time.

to limited mobility, such as injured legs, an inability to operate a vehicle, persons bed-ridden by illness, and persons who were wheelchair bound. These limitations caused elderly to succumb to fire within their place of residence, or if they made it to their vehicle, they were overtaken and killed by the firestorm within a mile or less of their homes. Other victims suffered deficits in perception due to the effects of dementia and physical and social isolation from their community. Some likely did not receive warning, because of not having a cell phone, living in an area with no cell service, lacking social and electronic media, or not receiving a door-to-door evacuation notice by emergency personnel. Apathy toward the emergency situation was also documented in some circumstances. It is telling that there is strong anecdotal evidence that elderly who survived the fire received direct assistance from family, friends, neighbors, or other private and public agencies (Bizjak et al. 2018; St. John et al. 2018).

\section{k. Tropical cyclones}

Tropical cyclones were a hazard that disproportionately affected elderly persons, and those with limited mobility and threat perception. Every $5 \mathrm{yr}$ bin in age groups over 75 experienced $>15 \%$ of their normalized fatalities as a result of tropical cyclones (Fig. 22). Because of Hurricane Katrina, Louisiana was associated with the most tropical-cyclone fatalities in the elderly group ( $84 \%$ ), followed by Mississippi (7\%), Florida $(4 \%)$, and Texas (2\%; see Fig. 10c). Also, because of Katrina, $94 \%$ of the elderly fatalities occurred during the month of August, and $58 \%$ of the elderly deaths were in the female population.

The tropical-cyclone fatalities analyzed in this study were strongly skewed toward Hurricane Katrina, which was the most impactful landfalling U.S. hurricane in terms of dollar damage (National Hurricane Center 2018). Katrina's strong prelandfall wind speeds combined with an above normal diameter aided in an exceptionally large storm surge (Irish et al. 2008; Needham and Keim 2014) that breached the levee system in New Orleans, Louisiana-the failure of the levee system led to flooding of approximately $80 \%$ of the city. Historically (1963-2012), drowning accounts for around $90 \%$ of tropical-cyclone fatalities attributable to the physical forces of a storm, that is, "direct" deaths-half of which are due to storm surge. This was also the case for Hurricane Katrina. The tremendous amount of deep fast-flowing water filling portions of New Orleans led to the deaths of hundreds of people by drowning. Others died in their homes and attics as they sought refuge from

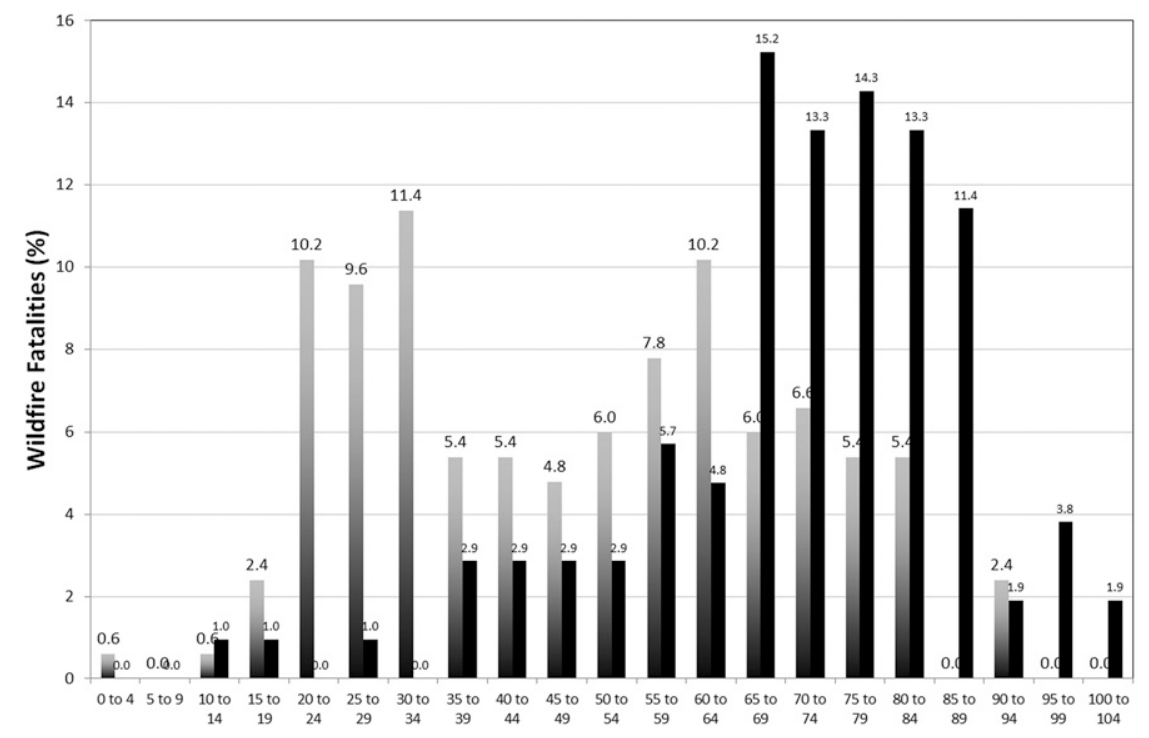

FIG. 21. Wildfire fatalities for each age group normalized by the total number of wildfire fatalities valid over 1996-2018 (gray bars) compared with wildfire fatalities from the 2017 and 2018 northern California wildfire events (black bars). 
TABLE 4. Ingredients that characterized the 2017 and 2018 deadly northern California wildfires.

\begin{tabular}{|c|c|}
\hline Ingredient & Description \\
\hline Meteorological & $\begin{array}{l}\text { Strong cross-barrier flow aiding in down- } \\
\text { slope mountain-wave winds collocated } \\
\text { with a very dry air mass and fuels fa- } \\
\text { vorable for extreme wildfire behavior }\end{array}$ \\
\hline Geographic & Lee side of a topographic ridge \\
\hline Community & $\begin{array}{l}\text { Population center embedded within the } \\
\text { urban-wildland interface with limited } \\
\text { or constricted escape routes }\end{array}$ \\
\hline Socioeconomic & $\begin{array}{l}\text { Above-normal elderly and disabled } \\
\text { population }\end{array}$ \\
\hline
\end{tabular}

flood waters. Katrina also produced an unprecedented storm surge along the Mississippi coast, which resulted in 180 deaths (Rappaport 2014).

Mortality studies showed that persons over the age of 60 were more likely to die during or after Katrina as a result of a lack of evacuation facilities; preexisting illnesses that made evacuation difficult, if not impossible; high levels of poverty; and isolation (Adams et al. 2011). In some cases, the sick and elderly were too feeble to endure the stress associated with evacuating, and thus they sheltered in their homes. Those sheltering at home were in some instances forced to move into their attic or onto their roof to evade rising flood waters. Those measures further added to the stress endured by the sick and elderly and contributed directly to death on occasion.

Additional studies showed that $65 \%$ of elderly in New Orleans lacked transportation options to evacuate (Baylor College of Medicine 2006). Some were without family, and some lacked mental or physical capacities necessary to evacuate on their own. Even those who managed to evacuate sometimes succumbed to failing health, partially because of a lack of family intervention, government infrastructure, and communication systems necessary for locating displaced persons. Some elderly were even too frail to return to their homes in New Orleans after the flood waters receded (Adams et al. 2011).

\section{Discussion and conclusions}

Differences in mobility and perception were examined for age groups impacted by weather hazards. Key findings from that analysis include the following:

- The relative immobility of the very young and some elderly resulted in a lower ability to physically respond to hazards such as heat, cold, wildfires, and tropical cyclones. For example, a very young child is not capable of removing his- or herself from a hot vehicle, an elderly person may be too frail to evacuate ahead of a hurricane, or an older person may fall outdoors in cold weather and cannot get up from the ground. The elderly may also lack a means of transportation, limiting their ability to evacuate, or they may have no place to which to evacuate.

- On the other hand, people aged from their teens through middle age could more readily evacuate a hazardous situation but were also more capable of physically entering a hazard zone. Such hazards in which physically mobile individuals entered included rip currents, avalanche zones, and outdoor activities exposing them to lightning.

- Perception in the elderly was potentially limited by apathy, social isolation, and dementia during wildfire

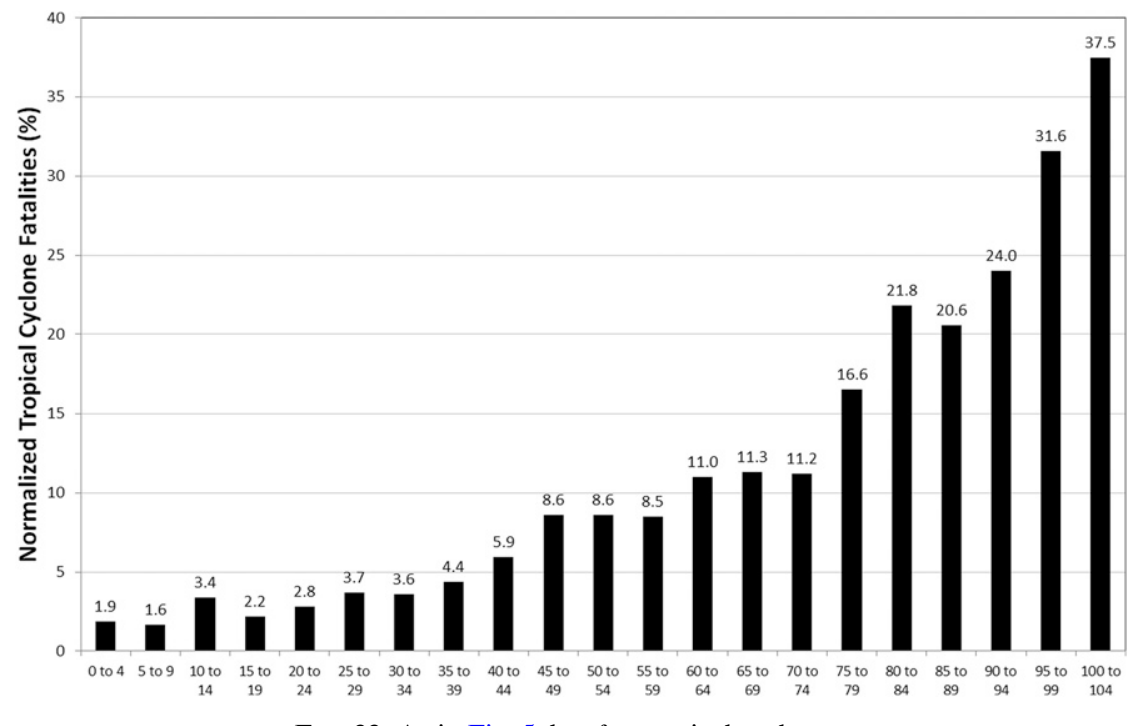

FIG. 22. As in Fig. 5, but for tropical cyclones. 
and tropical-cyclone hazards. A lack of technology may have also prevented portions of the elderly population from receiving warning information necessary for hazard evacuation - an issue particularly acute during deadly Northern California wildfire events.

- Very young children were also susceptible to perception limitations. For example, children playing next to flooded drainage systems may have been unaware of the deadly hazard lying right next to their feet. On the other hand, children left in a hot vehicle were victims of a lack of hazard awareness by their older caretakers.

- For persons in their teens and twenties, a lack of experience and a predisposition toward sensation seeking and risky behavior may have contributed to fatal outcomes in scenarios involving winter weather driving, rip currents, avalanches, and flooded roadways (Howland et al. 1996; Roberti 2004; Waylen and McKeena 2008; Gensini and Ashley 2009).

- One topic not objectively analyzed in this paper is hazard survivability. In other words, what were the number of people in an age group who were exposed to a hazard and survived?

This paper presents anecdotal evidence that weather fatalities were reduced when communities assisted such populations as the elderly and infirm who suffered from mobility and perception limitations. As demonstrated during the 2018 Paradise wildfire, physically handicapped and socially isolated elderly persons were most vulnerable to the fire-those who received assistance generally survived, while a large number who did not receive assistance died. The weather enterprise should embrace community activism through programs such as Weather-Ready Nation in order to promote outreach that assists vulnerable persons during emerging hazardous weather situations. Similar to Weather-Ready Nation, the Department of Homeland Security and the Federal Emergency Management Agency support the Community Emergency Response Team (CERT), which educates local volunteers about disaster preparedness and response for hazards that might impact their area. The CERT program is designed to allow local and state managers the flexibility to form their programs in a way best suited for their community - this in turn could be leveraged to assist vulnerable persons during potentially deadly weather scenarios.

Brooks and Doswell (2002) provide evidence that early education initiatives may yield positive results in the reduction of weather fatalities. They show that the lack of fatalities in the 5-23-yr-old age group affected by the 3 May 1999 violent tornado impacting Moore, Oklahoma, may have been due to education. For instance, $85 \%$ of junior high school students in Moore took some 
type of precautionary tornado action, and $70 \%$ indicated that they learned tornado safety precautions as part of their school curriculum. In the current study, normalized tornado fatalities peaked in the 5-9-yr-old age group and then fell to a minimum in the $15-19 \mathrm{yr}$ group. Perhaps that is evidence that the accumulation of tornado education and experience obtained by teenagers was enough to reduce fatalities, although it does not explain why fatalities rose once again going into middleaged groups. Figure 15 provides additional evidence showing that education and messaging may be yielding positive results in the reduction of fatalities-lightning deaths have declined from 1996 to 2018 during the weather enterprise campaign that encourages people to go indoors when thunder roars. Additional study on the temporal trends associated with age-related weather fatalities would be worthwhile.

The weather enterprise, including the NWS, is engaging the public through social media-providing forecast updates, watches, warnings, advisories, and weather education. However, a 2012 Pew Research Center survey showed that only $32 \%$ of people who are 65 and older used social media, whereas $77 \%-83 \%$ of people between the ages of 18 and 49 used social media (Duggan and Brenner 2013). A similar Pew Research Center survey found that $89 \%-94 \%$ of people in the 18-49-yr-old age group owned a "smart" telephone as compared with only $46 \%$ in the 65 -and-older group (https:// www.pewinternet.org/factsheet/mobile). Conversely, $85 \%$ of persons 65 or older received their news from TV, whereas only $27 \%$ of people aged from 18 to 29 used TV as a news source (Mitchell et al. 2016). The on-the-go source of weather information at the fingertips of younger people potentially serves as an important aid in averting fatal weather outcomes, especially when the weather enterprise tailors their messaging to the mobile media channels and audience (Eachus and Keim 2019). However, mobile weather messaging may not be reaching one of the most vulnerable population groups-the elderly. This stresses the point that weatherinformed members of society should reach out and aid less-informed vulnerable groups when weather emergencies become evident.

The authors echo the conclusions made by Ashley and Ashley (2008), who suggested that the weather enterprise target groups that are particularly vulnerable to weather hazards through specialized messaging strategies. For instance, wildfire messaging could remind community members to check on elderly neighbors, ensuring that they evacuate safely from an approaching fire; heat messaging could consistently remind people that the elderly and the very young are statistically most at risk to succumbing; surfzone messaging could highlight the fact that attempting to rescue someone often leads to a fatal outcome; and flood messaging could point to the fact that young children are tragically dying when they play next to and then fall into flooded drainages (Table 5). Perhaps most important is that encouraging communities to embrace the old-fashioned ideals of neighbors helping neighbors may be an important step in reducing weather fatalities and achieving a weatherready nation.

Acknowledgments. The authors thank Ryan Aylward, Mel Nordquist, Troy Nicolini, Sten Tjaden, Matthew Kidwell, and Tamara Lopez for their assistance during various stages of this research. In addition, the authors appreciate National Weather Service Western Region Headquarters for supporting this project. The authors also acknowledge the editorial guidance provided by Dr. Walker S. Ashley and the valuable suggestions made by three anonymous reviewers.

\section{REFERENCES}

Adams, V., S. R. Kaufman, T. V. Hattum, and S. Moody, 2011: Aging disaster: Mortality, vulnerability, and long-term recovery among Katrina survivors. Med. Anthropol., 30, 247 270, https://doi.org/10.1080/01459740.2011.560777.

Antonescu, B., and F. Cărbunaru, 2018: Lightning-related fatalities in Romania from 1999 to 2015. Wea. Climate Soc., 10, 241-252, https://doi.org/10.1175/WCAS-D-17-0091.1.

Ashley, S. T., and W. S. Ashley, 2008: Flood fatalities in the United States. J. Appl. Meteor. Climatol., 47, 805-818, https://doi.org/ 10.1175/2007JAMC1611.1.

Ashley, W. S., 2007: Spatial and temporal analysis of tornado fatalities in the United States: 1880-2005. Wea. Forecasting, 22, 1214-1228, https://doi.org/10.1175/2007WAF2007004.1.

_ and T. L. Mote, 2005: Derecho hazards in the United States. Bull. Amer. Meteor. Soc., 86, 1577-1592, https://doi.org/ 10.1175/BAMS-86-11-1577.

Baylor College of Medicine, 2006: Recommendations for best practices in the management of elderly disaster victims. AARP Rep., 44 pp., https://assets.aarp.org/www.aarp.org_/ articles/aboutaarp/baylor_best_practices_guide.pdf.

Bizjak, T., A. Yoon-Hendricks, P. Reese, and M. Sullivan, 2018: Many of the dead in Camp Fire were disabled, elderly. Could they have been saved? Sacramento Bee, accessed 31 July 2019, https://www.sacbee.com/news/california/fires/ article222044970.html.

Brooks, H. E., 2004: On the relationship of tornado path length and width to intensity. Wea. Forecasting, 19, 310-319, https://doi.org/ 10.1175/1520-0434(2004)019<0310:OTROTP>2.0.CO;2. , and C. A. Doswell III, 2002: Deaths in the 3 May 1999 Oklahoma City tornado from a historical perspective. Wea. Forecasting, 17, 354-361, https://doi.org/10.1175/1520-0434(2002)017<0354: DITMOC $>2.0 . \mathrm{CO} ; 2$.

Carbon, C., 2014: Understanding human perception by humanmade illusions. Front. Hum. Neurosci., 8, 1-6, https://doi.org/ 10.3389/fnhum.2014.00566.

Changnon, S. A., K. E. Kunkel, and B. C. Reinke, 1996: Impacts and responses to the 1995 heat wave: A call to action. Bull. 
Amer. Meteor. Soc., 77, 1497-1506, https://doi.org/10.1175/ 1520-0477(1996)077<1497:IARTTH>2.0.CO;2.

City of Chicago, 2019: Heat emergency mobilization. Accessed 31 July 2019, https://www.chicago.gov/city/en/depts/mopd/provdrs/ resource/alerts/2019/july/Heat_Emergency_Mobilization.html.

Clarke, P. J., T. Yan, F. Keusch, and N. A. Gallagher, 2015: The impact of weather on mobility and participation in older U.S. adults. Amer. J. Public Health, 105, 1489-1494, https://doi.org/ 10.2105/AJPH.2015.302582.

Colman, B. R., and C. F. Dierking, 1992: The Taku wind of southeast Alaska: Its identification and prediction. Wea. Forecasting, 7, 49-64, https://doi.org/10.1175/1520-0434(1992) 007<0049:TTWOSA $>2.0$. CO;2.

Curran, E. B., R. L. Holle, and R. E. Lopez, 2000: Lightning casualties and damages in the United States from 1959 to 1994. J. Climate, 13, 3448-3464, https://doi.org/10.1175/1520-0442(2000)013<3448: LCADIT $>2.0 . C O ; 2$.

Duggan, M., and J. Brenner, 2013: The demographics of social media users-2012. Pew Research Center, accessed 31 July 2019, https://www.pewinternet.org/2013/02/14/the-demographics-ofsocial-media-users-2012.

Eachus, J. D., and B. D. Keim, 2019: A survey for weather communicators: Twitter and information channel preferences. Wea. Climate Soc., 11, 595-607, https://doi.org/ 10.1175/WCAS-D-18-0091.1.

Gamble, J. L., and Coauthors, 2016: The impacts of climate change on human health in the United States: Populations of concern. GlobalChange.gov, accessed 31 July 2019, https://health2016.globalchange.gov/populations-concern.

Gensini, V., and W. Ashley, 2009: An examination of rip current fatalities in the United States. Nat. Hazards, 54, 159-175, https://doi.org/10.1007/s11069-009-9458-0.

Holle, R. L., 2016: A summary of recent national-scale lightning fatality studies. Wea. Climate Soc., 8, 35-42, https://doi.org/ 10.1175/WCAS-D-15-0032.1.

Howland, J., R. Hingson, T. W. Mangione, N. Bell, and S. Bak, 1996: Why are most drowning victims men? Sex differences in aquatic skills and behaviors. Amer. J. Public Health, 86, 93-96, https://doi.org/10.2105/AJPH.86.1.93.

Irish, J. L., D. T. Resio, and J. J. Ratcliff, 2008: The influence of storm size on hurricane surge. J. Phys. Oceanogr., 38, 20032013, https://doi.org/10.1175/2008JPO3727.1.

Jones, C., F. Fujioka, and L. M. V. Carvalho, 2010: Forecast skill of synoptic conditions associated with Santa Ana winds in Southern California. Mon. Wea. Rev., 138, 4528-4541, https:// doi.org/10.1175/2010MWR3406.1.

Kalkstein, L. S., P. F. Jamason, J. S. Greene, J. Libby, and L. Robinson, 1996: The Philadelphia hot weather-health watch/warning system: Development and application, summer 1995. Bull. Amer. Meteor. Soc., 77, 1519-1528, https://doi.org/10.1175/1520-0477(1996)077<1519:TPHWHW> 2.0.CO;2.

Klinenberg, E., 2002: Heat Wave: A Social Autopsy of Disaster in Chicago. University Chicago Press, 324 pp.

Lavell, A., M. Oppenheimer, C. Diop, J. Hess, R. Lempert, J. Li, R. Muir-Wood, and S. Myeong, 2012: Climate change: New dimensions in disaster risk, exposure, vulnerability, and resilience. Managing the Risks of Extreme Events and Disasters to Advance Climate Change Adaptation, C. B. Field et al., Eds., Cambridge University Press, 25-64.

Lindley, T. T., and Coauthors, 2014: Southern Great Plains wildfire outbreaks. Electron. J. Severe Storms Meteor., 9 (2), https:// ejssm.org/ojs/index.php/ejssm/article/viewArticle/132
Mass, C. F., and D. Oven, 2019: The Northern California wildfires of 8-9 October 2017: The role of a major downslope wind event. Bull. Amer. Meteor. Soc., 100, 235-256, https://doi.org/ 10.1175/BAMS-D-18-0037.1.

Mitchell, A., J. Gottfried, M. Barthel, and E. Shearer, 2016: The modern news consumer: News attitudes and practices in the digital era. Pew Research Center, accessed 31 July 2019, https://www.journalism.org/2016/07/07/the-modernnews-consumer/.

National Hurricane Center, 2018: Costliest U.S. tropical cyclones tables updated. NOAA Doc., 3 pp., https://www.nhc.noaa.gov/ news/UpdatedCostliest.pdf.

Nauslar, N. J., J. T. Abatzoglou, and P. T. Marsh, 2018: The 2017 North Bay and Southern California fires. A case study. Fire, 1, 18, https://doi.org/10.3390/FIRE1010018.

Needham, H. F., and B. D. Keim, 2014: Correlating storm surge heights with tropical cyclone winds at and before landfall. Earth Interact., 18, https://doi.org/10.1175/2013EI000558.1.

NWS, 2018: Impact-based decision support services for NWS core partners. National Weather Service Service Description Doc., 24 pp., https://www.nws.noaa.gov/im/IDSS_SDD_V1_0.pdf.

__, 2019a: Building a Weather-Ready Nation: 2019-2022 strategic plan. NOAA Doc., 28 pp., https://www.weather.gov/media/wrn/ NWS_Weather-Ready-Nation_Strategic_Plan_2019-2022.pdf.

_ 2019b: "When thunder roars, go indoors!"-_Lightning safety awareness. NOAA, accessed 26 August 2019, https:// www.weather.gov/ind/LightningSafetyAwareness.

Palecki, M. A., S. A. Changnon, and K. E. Kunkel, 2001: The nature and impacts of the July 1999 heat wave in the midwestern United States: Learning from the lessons of 1995. Bull. Amer. Meteor. Soc., 82, 1353-1367, https://doi.org/10.1175/15200477(2001)082<1353:TNAIOT $>2.3$. CO;2.

Peden, M., K. Oyegbite, J. Ozanne-Smith, A. A. Hyder, C. Branche, A. K. M. Fazlur Rahman, F. Rivara, and K. Bartolomeos, Eds., 2008: World report on child injury prevention. WHO Rep., 211 pp., https://apps.who.int/ iris/bitstream/handle/10665/43851/9789241563574_eng.pdf; jsessionid = A161B206DC6AEA47C087BFAD3BAD1020? sequence $=1$.

Raga, G. B., M. G. de la Parra, and B. Kucienska, 2014: Deaths by lightning in Mexico (1979-2011): Threat or vulnerability? Wea. Climate Soc., 6, 434-444, https://doi.org/10.1175/WCASD-13-00049.1.

Raphael, M. N., 2003: The Santa Ana winds of California. Earth Interact., 7, https://doi.org/10.1175/1087-3562(2003)007<0001: TSAWOC $>2.0 . \mathrm{CO} ; 2$.

Rappaport, E. N., 2014: Fatalities in the United States from Atlantic tropical cyclones: New data and interpretation. Bull. Amer. Meteor. Soc., 95, 341-346, https://doi.org/ 10.1175/BAMS-D-12-00074.1.

Riebsame, W. E., H. F. Diaz, T. Moses, and M. Price, 1986: The social burden of weather and climate hazards. Bull. Amer. Meteor. Soc., 67, 1378-1388, https://doi.org/10.1175/15200477(1986)067<1378:TSBOWA > 2.0.CO;2.

Roberti, J. W., 2004: A review of behavioral and biological correlates of sensation seeking. J. Res. Pers., 38, 256-279, https:// doi.org/10.1016/S0092-6566(03)00067-9.

Rodriguez, M., 2014: 26 died from cold this year. Chicago Tribune, accessed 31 July 2019, https://www.chicagotribune.com/news/ ct-xpm-2014-03-09-ct-cold-deaths-met-20140309-story.html.

Root, C. J., 1937: Deaths during the heat wave of July, 1936 at Detroit. Bull. Amer. Meteor. Soc., 18, 232-236, https://doi.org/ 10.1175/1520-0477-18.6-7.232. 
Rosso, A. L., J. A. Taylor, L. P. Tabb, and Y. L. Michael, 2013: Mobility, disability, and social engagement in older adults. J. Aging Health, 25, 617-637, https://doi.org/10.1177/0898264313482489.

Shoyinka, S., 2019: Heat safety policy. City of Philadelphia Rep., 17 pp., https://dbhids.org/trainings/Heat\%20Safety_v5/story_content/ external_files/Heat\%20Safety\%20Bulletin\%202019\%20.pdf.

Stein, S. M., S. J. Comas, J. P. Menakis, M. A. Carr, S. I. Stewart, H. Cleveland, L. Bramwell, and V. C. Radeloff, 2013: Wildfire, wildlands, and people: Understanding and preparing for wildfire in the wildland-urban interface. USDA General Tech. Rep. RMRSGTR-299, 36 pp., https://www.fs.fed.us/rm/pubs/rmrs_gtr299.pdf.
St. John, P., J. Serna, and R.-G. Lin II, 2018: Here's how Paradise ignored warnings and became a deathtrap. Los Angeles Times, accessed 31 July 2019, https://www.latimes. com/local/california/la-me-camp-fire-deathtrap-20181230story.html.

Tacoli, C., 2009: Crisis or adaptation? Migration and climate change in a context of high mobility. Environ. Urbanization, 21, 513-525, https://doi.org/10.1177/0956247809342182.

Waylen, A. E., and F. P. McKeena, 2008: Risky attitudes towards road use in pre-drivers. Accid. Anal. Prev., 40, 905-911, https:// doi.org/10.1016/j.aap.2007.10.005. 